\title{
GPS Radio Occultation: Results from CHAMP, GRACE and FORMOSAT-3/COSMIC
}

\author{
Jens Wickert ${ }^{1,}{ }^{*}$, Grzegorz Michalak ${ }^{1}$, Torsten Schmidt ${ }^{1}$, Georg Beyerle ${ }^{1}$, Chio-Zong Cheng ${ }^{2}$, \\ Sean B. Healy ${ }^{3}$, Stefan Heise ${ }^{1}$, Cheng-Yung Huang ${ }^{4}$, Norbert Jakowski ${ }^{5}$, Wolfgang Köhler ${ }^{1}$, \\ Christoph Mayer $^{5}$, Dave Offiler ${ }^{6}$, Eiji Ozawa ${ }^{7}$, Alexander G. Pavelyev ${ }^{8}$, \\ Markus Rothacher ${ }^{1}$, Byron Tapley ${ }^{9}$, and Christina Arras ${ }^{1}$ \\ ${ }^{1}$ Helmholtz Centre Potsdam, GFZ German Research Centre for Geosciences, Potsdam, Germany \\ ${ }^{2}$ National Cheng Kung University (NCKU), Tainan, Taiwan, ROC \\ ${ }^{3}$ European Centre for Medium Range Forecasts (ECMWF), Reading, UK \\ ${ }^{4}$ National Space Organization (NSPO), Hsinchu, Taiwan, ROC \\ ${ }^{5}$ Deutsches Zentrum für Luft- und Raumfahrt (DLR), Neustrelitz, Germany \\ ${ }^{6}$ Met Office, Exeter, UK \\ ${ }^{7}$ Japan Meteorological Agency (JMA), Tsukuba, Japan \\ ${ }^{8}$ Institute for Radioengineering and Electronics (IRE), Moscow, Russia \\ ${ }^{9}$ University of Texas, Austin, US
}

Received 27 June 2007, accepted 26 December 2007

\begin{abstract}
The Taiwan/US FORMOSAT-3/COSMIC (FORMOsa SATellite mission - 3/Constellation Observing System for Meteorology, Ionosphere and Climate) satellite constellation was successfully launched on 14 April 2006. It is expected to leverage the use of the GPS (Global Positioning System) radio occultation data for atmospheric and ionospheric research to improve global weather forecasts and aid climate change related studies. FORMOSAT-3/COSMIC, together with the European MetOp, German CHAMP and US/German GRACE-A satellites, form a 9 satellite constellation for precise atmospheric sounding on a global scale. This satellite constellation is expected to provide about 3500 occultation measurements daily.

Recent results and the status of the CHAMP and GRACE-A orbit and occultation data analysis are reviewed and complemented with a review of initial results from FORMOSAT-3/COSMIC at GFZ. The significantly increased potential of the CHAMP, GRACE-A and FORMOSAT-3/COSMIC constellation for atmospheric studies, compared to single satellite missions, is demonstrated for selected applications such as global monitoring of water vapor distributions, tropopause parameters and ionospheric irregularities.
\end{abstract}

Key words: Radio occultation, Weather forecast, Tropopause, Ionosphere, Water vapor, Sporadic E-layer

Citation: Wickert, J., G. Michalak, T. Schmidt, G. Beyerle, C. Z. Cheng, S. B. Healy, S. Heise, C. Y. Huang, N. Jakowski, W. Köhler, C. Mayer, D. Offiler, E. Ozawa, A. G. Pavelyev, M. Rothacher, B. Tapley, and C. Arras, 2009: GPS radio occultation: Results from CHAMP, GRACE and FORMOSAT-3/COSMIC. Terr. Atmos. Ocean. Sci., 20, 35-50, doi: 10.3319/TAO.2007.12.26.01(F3C)

\section{INTRODUCTION}

The year 2006 marks the beginning of an era in which a multi-satellite constellation is used for precise atmospheric sounding on a global scale using GPS radio occultation (RO, e.g., Yunck et al. 2000). In addition to the German CHAMP (CHAllenging Minisatellite Payload) satellite (e.g., Wickert et al. 2001a; Reigber et al. 2005), which since its launch in

\footnotetext{
* Corresponding author

E-mail:wickert@gfz-potsdam.de
}

2001 has provided occultation data almost continuously (e.g., Wickert et al. 2006a, b), measurements from several additional missions became available in 2006. The US/ German GRACE-A satellite (e.g., Dunn et al. 2003; Tapley and Reigber 2004) has provided occultation data continuously since 22 May 2006. The six satellites of the Taiwan/ US FORMOSAT-3/COSMIC mission were successfully launched on 14 April 2006 (Cheng et al. 2006; Anthes et al. 2008 ) and once, in the final orbital configuration more than 
2500 profiles per day are expected. The European operational weather satellite MetOp was launched on 19 October 2006 and initial results of the GRAS (GNSS Receiver for Atmospheric Sounding; see, e.g., Montenbruck et al. 2008) on 27 October, indicated the potential for providing more than 600 measurements per day (www.eumetsat.int; von Engeln et al. 2007). This multi-satellite configuration was further extended by the German TerraSAR-X with an Integrated GPS Occultation Receiver (IGOR) receiver on board when it was launched on 15 June 2007 via a Russian Dnepr-1 rocket from Baikonur (Russia). The measurements from all these satellites enhance the potential of the GPS occultation technique for several applications in atmospheric research, weather forecast and climate change related studies.

We briefly review the status and the operational data analysis of GPS RO aboard CHAMP and GRACE-A and present initial GFZ results from the FORMOSAT-3/COSMIC.

\section{HISTORY AND STATUS OF RADIO OCCULTATION ABOARD CHAMP AND GRACE}

CHAMP reached its $7^{\text {th }}$ anniversary in orbit on 15 July 2007. A successful orbit uplift of $19 \mathrm{~km}$ was performed at the end of March 2006 to extend CHAMP's lifetime, which is currently expected to end in 2009. The satellite and instrument are in excellent condition and the operation is currently funded until 2009. GPS radio occultation aboard CHAMP was activated on 11 February 2001, more than 300000 profiles have been derived as of mid September 2007 (Fig. 1). Ionospheric profiles from CHAMP are available since 11 April 2001 (see, e.g., Jakowski et al. 2002).

Initial occultation measurements from GRACE were recorded during a $25 \mathrm{~h}$ period on 28/29 July 2004 aboard the GRACE-B satellite (Wickert et al. 2005; Beyerle et al. 2006). A longer period of GRACE-A measurements (41 days) was obtained between 12 January and 20 February 2006 before continuous activation began on 22 May 2006 (Fig. 1). Ionospheric profiles from GRACE-A are continuously available since 28 February 2007. The mission duration of GRACE is currently expected to last until $2012-2015$.

A new level as far as the number of recorded occultations is concerned, was reached after the launch of the FORMOSAT-3/COSMIC satellites on 15 April 2007 (Fig. 2). Beginning in the autumn of 2006, up
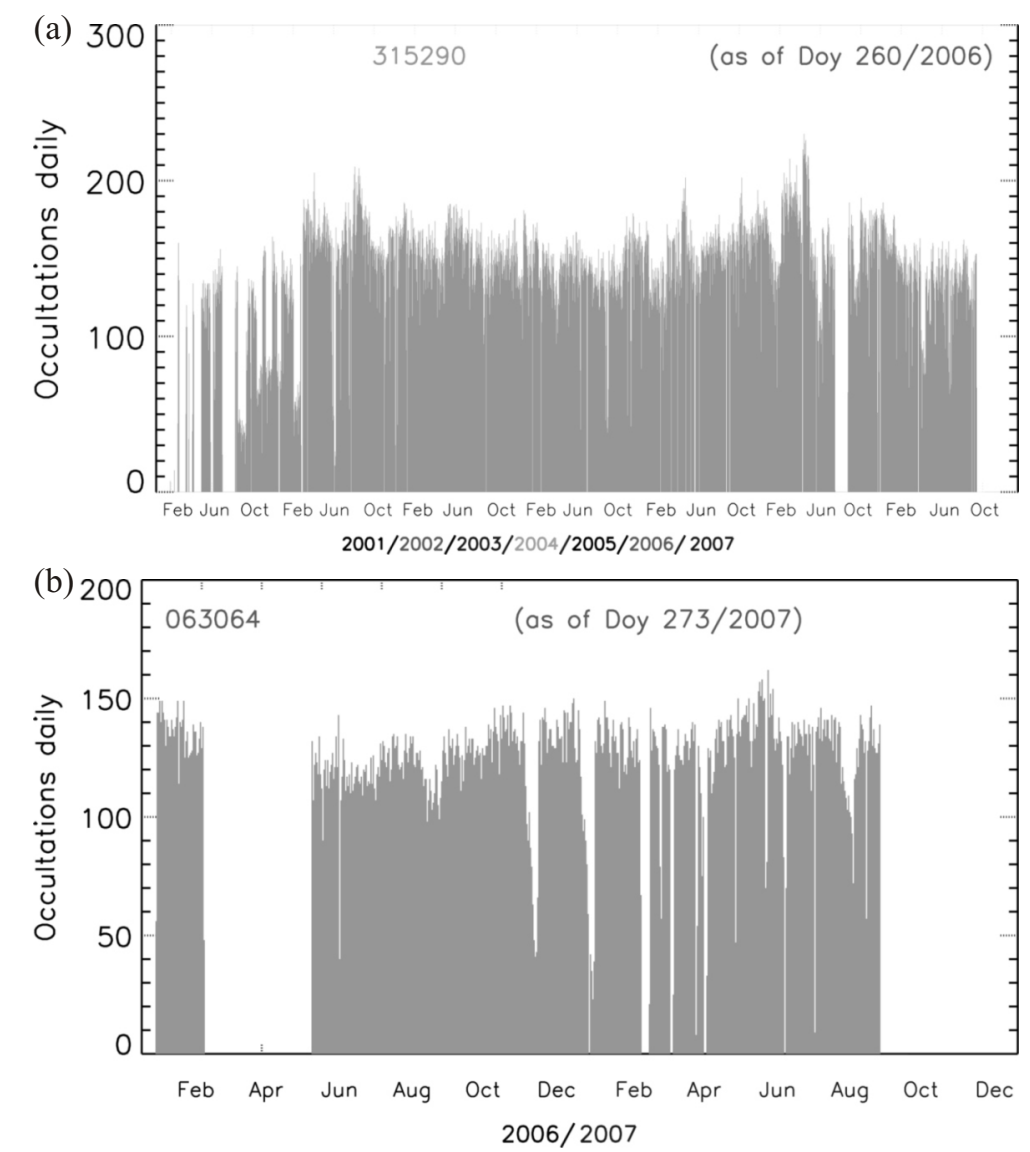

Fig. 1. Number of daily vertical atmospheric profiles, derived from (a) CHAMP and (b) GRACE-A GPS occultation measurements (GFZ processing). For the 2252 days of CHAMP RO activation 315290 profiles have been collected (on average about 140 per day) as of 17 September 2007. The number of available profiles from GRACE-A for 526 days of RO activation is 63064 as of 30 September 2007 (on average about 120 per day). The profiles from CHAMP form the first long-term RO data set which is expected to last until the end of 2009.

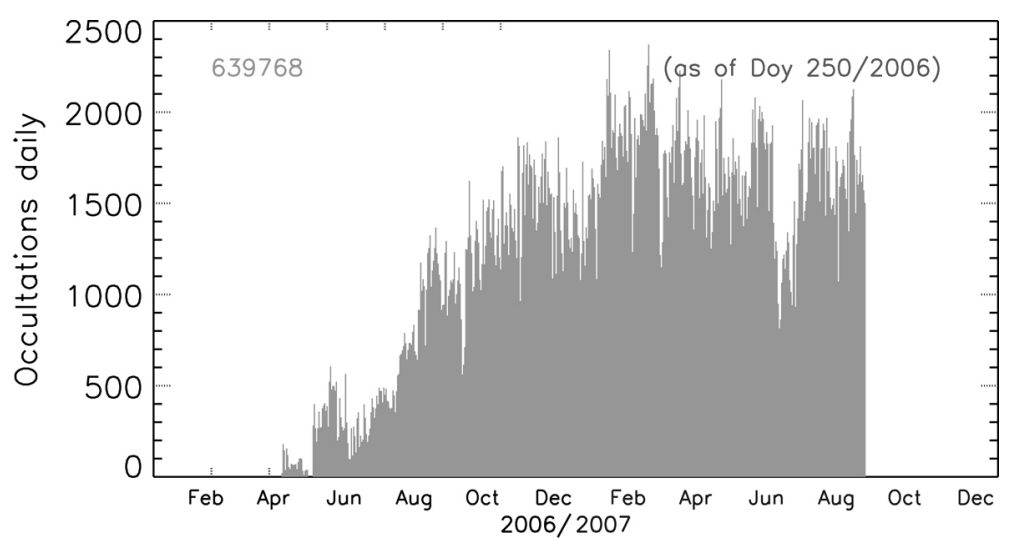

Fig. 2. Number of vertical atmospheric profiles from FORMOSAT-3/COSMIC as of 7 September 2007 (504 days, on average about 1270 per day). The data are provided by UCAR (University Corporation for Atmospheric Research) via www.cosmic .ucar.edu. 
to 2000 high quality profiles per day have been provided to the scientific user community. More than 2500 daily measurements are expected after reaching the final orbital configuration in 2007 (Schreiner et al. 2007; Anthes et al. 2008).

\section{OCCULTATION DATA ANALYSIS}

CHAMP and GRACE-A orbit and occultation data are operationally analyzed by GFZ beginning with raw data (GPS observations of the zenith and occultation antenna) up to higher level data products, the globally distributed vertical profiles of atmospheric parameters (see, e.g., Wickert et al. 2004a). Ionospheric occultation data are analyzed at the German Aerospace Center (DLR) Neustrelitz, Germany (e.g., Jakowski 2005). FORMOSAT-3/COSMIC data will be processed at GFZ for selected time periods.

\subsection{Ground Infrastructure}

The operational occultation ground infrastructure from GFZ is used for receiving and analyzing the CHAMP and GRACE-A data. It consists of a polar and mid-latitude receiving station (Ny Ålesund, Spitsbergen, $79.0^{\circ} \mathrm{N}, 11.5^{\circ} \mathrm{E}$ and Neustrelitz, Germany, $53.1^{\circ} \mathrm{N}, 13.1^{\circ} \mathrm{E}$, DLR), a high rate and low latency fiducial network of globally distributed GPS ground stations (jointly operated with Jet Propulsion Laboratory, JPL), the automated satellite orbit and occultation processing systems and GFZ's data archive. The operational capability and interplay of these components allow for the demonstration of a near-real time (NRT) occultation data analysis, which is almost continuously demonstrated with CHAMP and GRACE-A (see also section 3.4). A more detailed overview on the occultation infrastructure and relevant references are given by Wickert et al. (2004a).

\subsection{Precise Satellite Orbit Determination}

Details of the GFZ precise determination of GPS and CHAMP satellite positions, velocities and clocks are given, e.g., by König et al. (2005, 2006). This processing system is also used for the GRACE-A data analysis. The orbit product for the regular GFZ occultation analysis is denoted as Rapid Science Orbit (RSO). Fig. 3 shows a comparison of CHAMP and GRACE-A RSO data and Satellite Laser Ranging (SLR) measurements. The mean deviation in 2007 is $5.9 \mathrm{~cm}$ for CHAMP and $4.7 \mathrm{~cm}$ for GRACE-A.

Michalak et al. (2007a) provided a detailed study of FORMOSAT-3/COSMIC orbits by GFZ for the period between 4 and 7 August 2006, when complete GPS data coverage for the FORMOSAT-3/COSMIC satellites was available. Orbits were derived for all 6 satellites using the operational orbit processing system for CHAMP and GRACE-A. This system was extended to use FORMOSAT-3/COSMIC SST (satellite-satellite tracking) and attitude data. Since SLR data for FORMOSAT-3/COSMIC are not available for external validation, the orbits were compared with University Corporation for Atmospheric Research (UCAR) operational orbits. An example for these comparisons is provided in Fig. 4. The mean external 3-d position accuracy resulting from these comparisons for all 6 satellites is $23 \mathrm{~cm}$, for the velocity the accuracy amounts to $0.24 \mathrm{~mm} \mathrm{~s}^{-1}$. The internal position accuracy of GFZ orbits from the overlaps is better and amounts to $13.1 \mathrm{~cm}$. This (a)

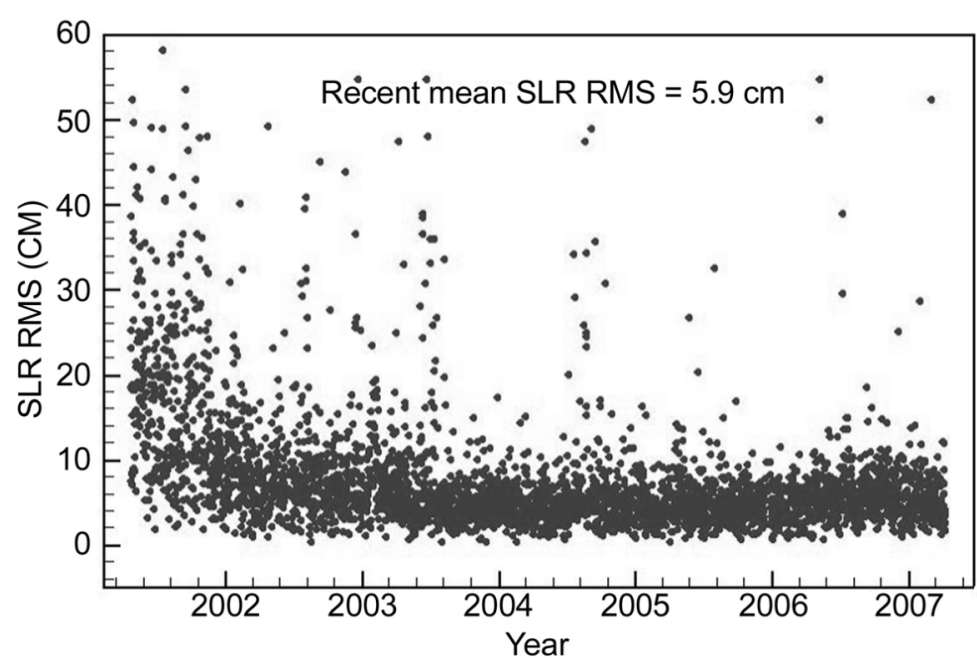

(b)

GRACE-A RSO

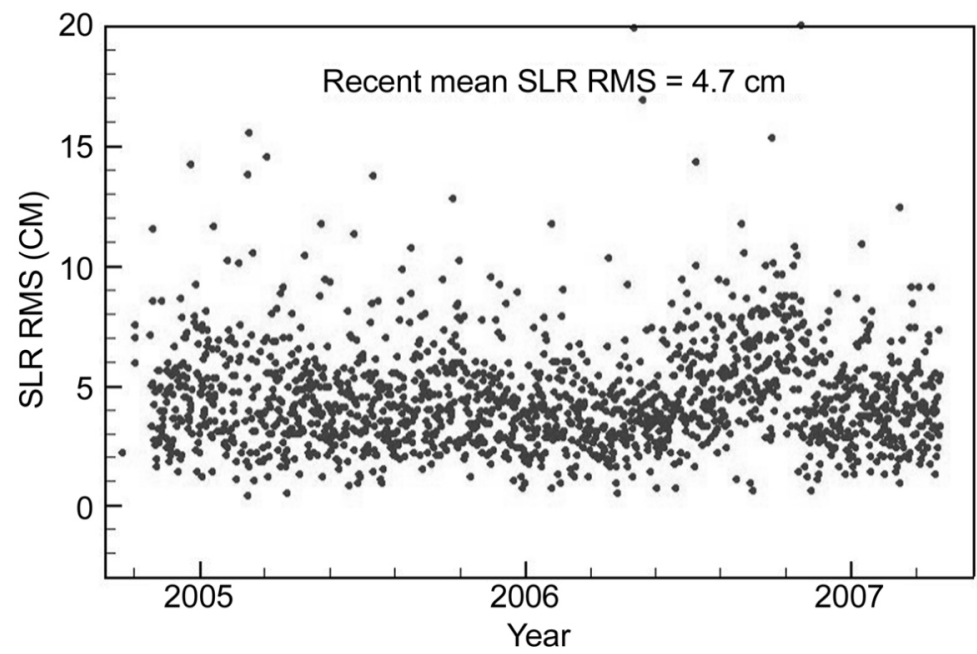

Fig. 3. Accuracy of LEO (Low Earth Orbiter) RSOs obtained from comparison with SLR measurements. (a) CHAMP (24 April 2001 - 11 April 2007). (b) GRACE-A (6 October 2004 - 11 April 2007). The mean RMS for CHAMP (5.9 cm) and GRACE-A $(4.7 \mathrm{~cm})$ is calculated for time period since January 2007. 


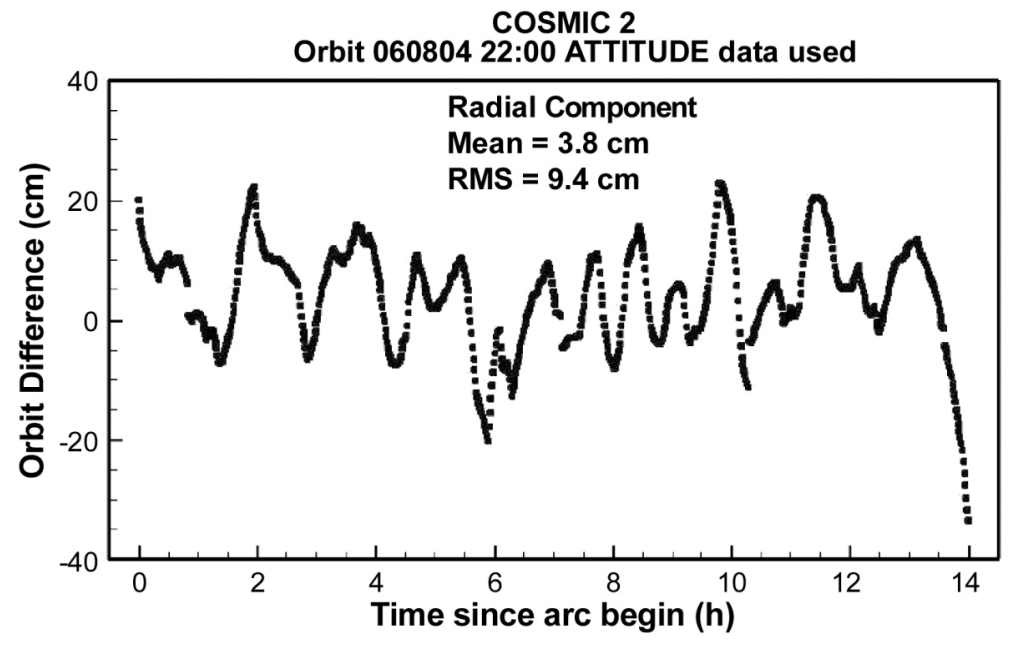

Fig. 4. An example from the initial results of the precise orbit determination for FORMOSAT-3/COSMIC at GFZ. The plot shows the difference in radial component between one $14 \mathrm{~h} \mathrm{GFZ}$ arc and corresponding operational UCAR orbits for FORMOSAT-3/COSMIC satellite 2 (4/5 August 2006). The mean deviation is $3.8 \mathrm{~cm}$ and corresponding RMS is $9.4 \mathrm{~cm}$.

value is comparable to the UCAR internal position precision of $15.2 \mathrm{~cm}$. For the internal velocity accuracy we have obtained $0.19 \mathrm{~mm} \mathrm{~s}^{-1}$. This is nearly twice the UCAR value, $0.11 \mathrm{~mm} \mathrm{~s}^{-1}$. The large difference between internal and external orbit accuracy suggests problems of systematic nature which will be investigated in the future. Currently, GFZ is also prepared to operationally generate FORMOSAT-3/ COSMIC orbits in a near-real time mode with less stringent accuracy requirements. We note that information on the relationship between orbit accuracy and atmospheric parameters can be found in Kursinski et al. 1997; Rocken et al. 1997; Wickert et al. 2001b; or Wickert 2002.

\subsection{Derivation of Vertical Atmospheric Profiles}

The double-difference technique (e.g., Wickert et al. 2001b) is currently applied for the CHAMP standard processing. Near-real time data (see section 3.4) are analyzed using the space-based single difference technique (Wickert et al. 2002). The measurements from GRACE-A were analyzed applying the zero-difference technique (Beyerle et al. 2006) which is implemented in the operational occultation analysis system from GFZ (e.g., Wickert et al. 2005). The zero-difference technique does not require inclusion of reference links from space- or ground-based receivers. Data from both GRACE satellites were processed using identical algorithms. We note that GRACE-B occultations (except the initial measurements, see section 2) were activated only for a short period between 1400 UTC 23 and 1200 UTC 30 September 2005. During this time GRACE-B trailed GRACE-A and its occultation antenna pointed to anti-velocity direction. On 10 December 2005 the order of the satellites was reversed. From 1231 GRACE-B occultations 1113 profiles $(90.4 \%)$ were derived and compared with ECMWF. The validation results (Wickert et al. 2006b) were found to be nearly identical with those from GRACE-A. The major difference between the GRACE satellites is the better value for the long-term stability of the Ultra Stable Oscillator (USO) aboard GRACE-B (about $30 \mathrm{~ns} \mathrm{~s}^{-1}$ ) compared to GRACE-A (about $230 \mathrm{~ns} \mathrm{~s}^{-1}$ ). Atmospheric bending angles are derived from the time derivative of the excess phase after appropriate filtering. The ionospheric correction is performed by linear combination of the separately derived L1 and L2 bending angle profiles (Vorob'ev and Krasnil'nikova 2004). To correct for the effect of tropospheric multipath, below $15 \mathrm{~km}$, the Full Spectrum Inversion (FSI) technique, a wave optics based analysis method, is applied (Jensen et al. 2003).

Vertical profiles of atmospheric refractivity are derived from the ionosphere corrected bending angle profiles by use of the Abel inversion technique. For dry air, the density profiles are obtained from the relationship between density and refractivity. Pressure and dry temperature are obtained applying the hydrostatic equation and the equation of state for an ideal gas. Basics of the GPS radio occultation technique and the derivation of atmospheric parameters are described by Kursinski et al. (1997). The scientific software algorithms for the calculation of the atmospheric profiles are embedded into a software system (CAP, CHAMP Atmosphere Processor), which implements the automation (Schmidt et al. 2005a) of the standard but also NRT data analysis.

An improved (in relation to GFZ software 005, see e.g., Wickert et al. 2005) processing software has been utilized for the NRT data analysis from CHAMP and GRACE-A. Hereby, the application of the single difference technique (CHAMP) almost completely eliminates the influence of irregularities which are introduced to the CHAMP data by periodic clock adjustments to achieve a $1 \mu$ s maximum deviation from coordinate time. However, a slight influence from these irregularities remains in the form of additional noise (introduced by the ionosphere correction of the reference link) and reduces the data quality at stratospheric altitudes. GRACE-A processing needs no inclusion of a reference link (zero differencing, use of an ultra-stable oscillator as satellite clock), therefore the additional noise, observed in the CHAMP data, is avoided. As a result, already the analysis of the first larger data sets from CHAMP and GRACE-A (Fig. 5) indicate reduced bias and also RMS of the GRACEA refractivity profiles to the operational model from the Met Office above $25 \mathrm{~km}$ in relation to the CHAMP data. This is regarded as indication of a higher quality of the GRACE-A 
data compared to CHAMP at higher altitudes. The lower troposphere bias of the improved profiles (NRT, Fig. 5) is reduced in relation to version 005 to values below $0.5 \%$ by im- proved implementation of the wave optics based data analysis and more strict quality control. This slightly decreases the lower troposphere data yield in relation to the

(a)

GFZ processed CHAMP data.global
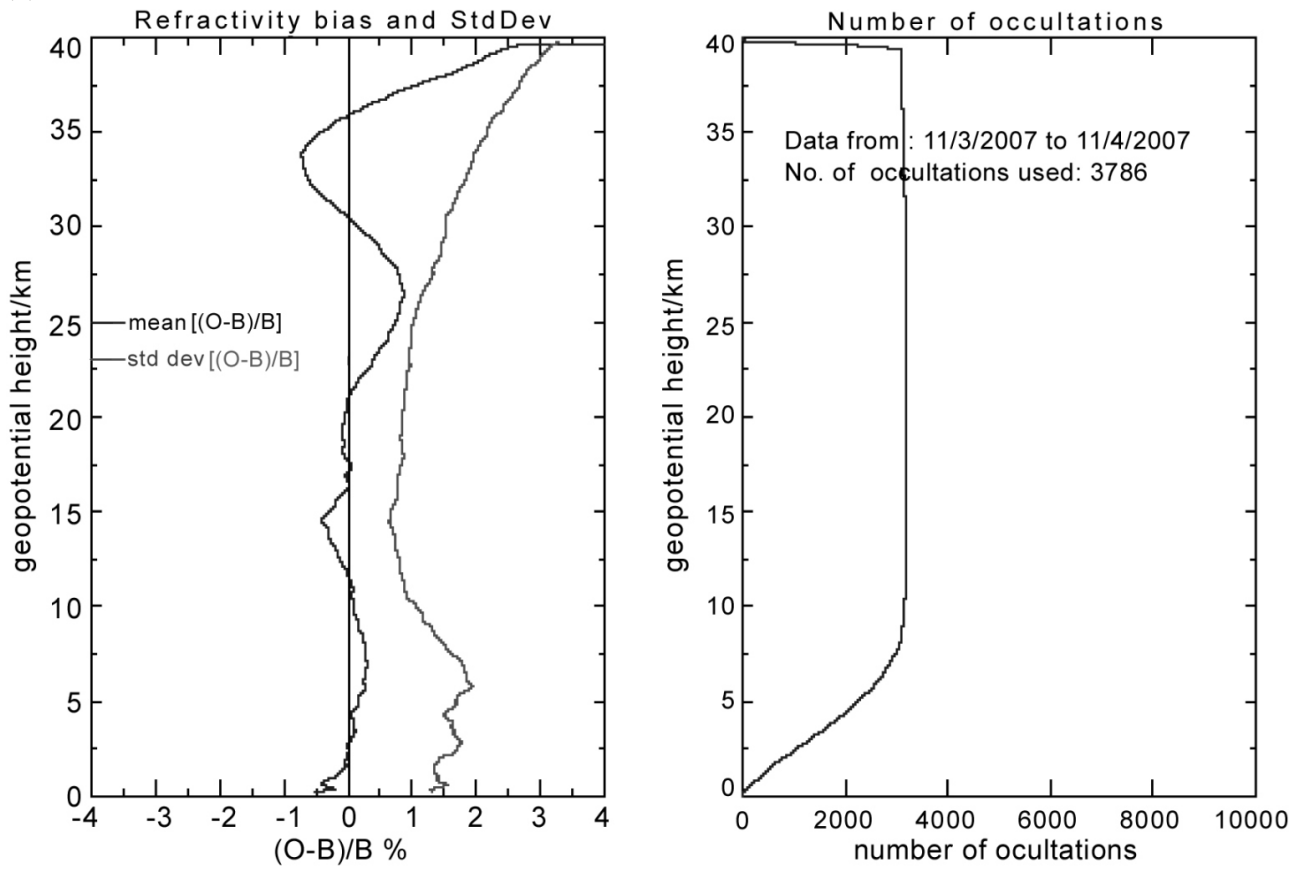

Plotted at: 04:25 11-Apr-0007

(b)

GFZ processed GRACE-A data. global
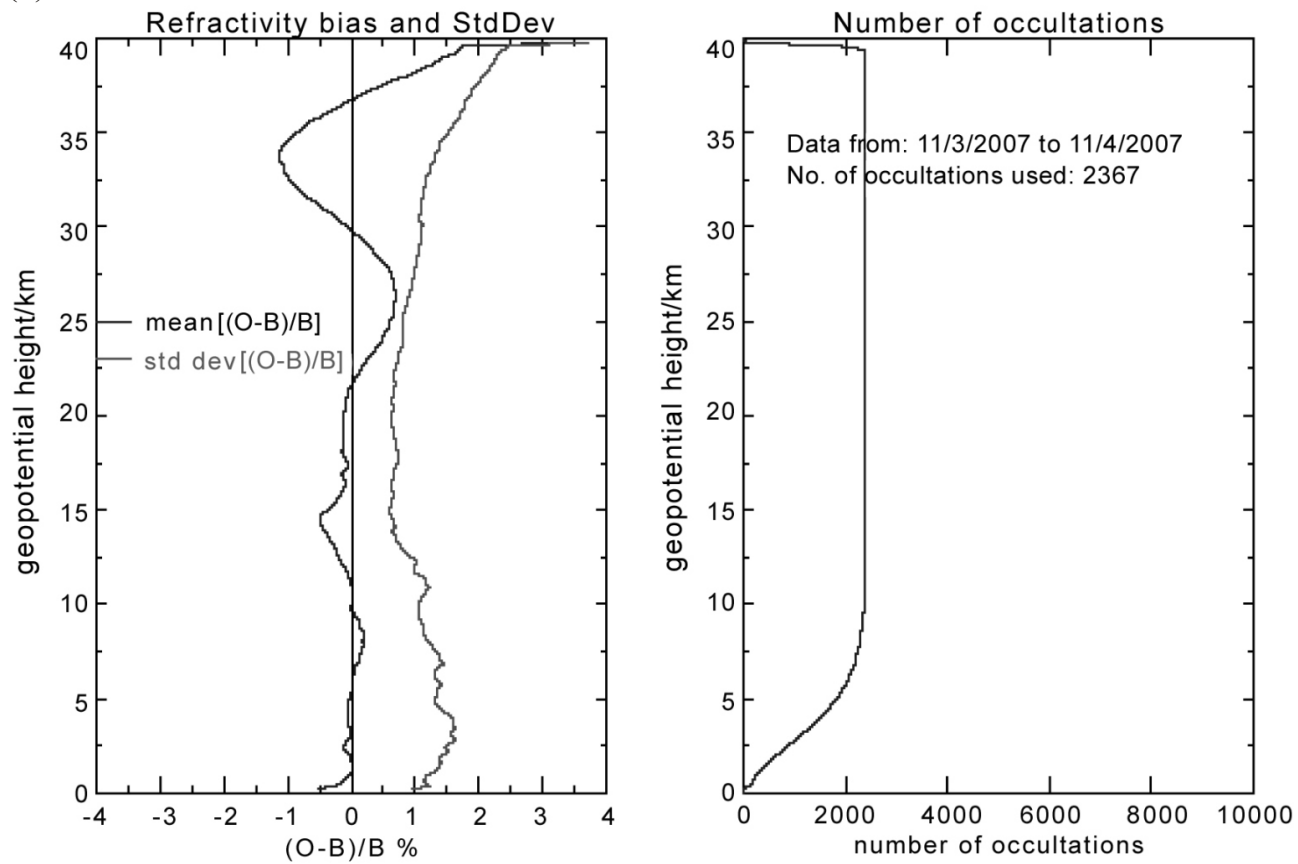

Plotted at: 04:26 11-Apr-2007

Fig. 5. Statistical comparison of vertical refractivity profiles (NRT data analysis) from (a) CHAMP (3186 profiles) and (b) GRACE-A (2387 profiles) between 11 March and 11 April 2007 with operational analyses from the Met Office [original quality monitoring plots from GRAS-SAF (GRAS Satellite Application Facility); black: mean deviation, grey: standard deviation]. Note that the S-shaped bias at upper levels is thought to be model-related, and not a feature of the RO data. (b) shows the number of compared data points as a function of altitude. 
005 product version (for validation results of 005 see, e.g., Wickert et al. 2005). We note however, that the observed deviations also can be due to weaknesses of the meteorological analyses.

Ionospheric profiles from CHAMP and GRACE-A measurements are generated by an automated processing system at DLR in Neustrelitz. The retrieval algorithm is based on a tomographic approach dividing the ionosphere and plasmasphere into spherical shells with upward growing thickness and constant electron density inside. Due to the low orbit height of CHAMP below $450 \mathrm{~km}$ (often within the F-layer of the vertical electron density distribution), the upper boundary problem is more challenging compared to LEOs at higher orbit. A specific model assisted technique has been developed using an adaptive model for the topside ionosphere and plasmasphere above the CHAMP orbit height. The model is based on a Chapman layer function completed by a plasmaspheric term with exponentially decreasing electron density vs. altitude. Model parameters such as the plasma scale height at the upper boundary are determined in a few iterations in order to ensure a smooth transition between model values and measurements (Jakowski et al. 2002). Due to the tomographic approach no spherical symmetry assumption is needed and additional information from ground based GPS measurements, ionospheric models and/or additional vertical sounders can improve the retrieval. These data, e.g., can provide information on horizontal gradients of the electron density distribution and improve the retrieval. The analysis software is embedded in a corresponding dynamically configurable automated data processing system (Wehrenpfennig et al. 2001). Fig. 6 shows two typical profiles, which were derived from the first GRACE-A ionospheric occultation measurements.

A major advantage of FORMOSAT-3/COSMIC data compared to CHAMP and GRACE-A is the improved data quality, combined with higher yield in the lower troposphere. This is achieved by the application of the OpenLoop (OL) signal tracking technique by the BlackJack GPS receiver (e.g., Beyerle et al. 2006; Sokolovskiy et al. 2006a, b). OL also allows for the tracking of rising occultations.

OL data processing needs specific modification and extension of the inversion software, which is used for the processing of the Closed Loop (CL) data from CHAMP and GRACE-A. Figure 7 shows the first result for a rising occultation from FORMOSAT-3/COSMIC generated with the operational GFZ processing software. The measurements were analyzed using the atmospheric excess phase data provided by UCAR. The reconstruction of the final phase from the model and the differential phase was performed using the navigation bit information from a supporting GPS ground network, also provided by UCAR (using the algorithm according to Sokolovskiy et al. 2006a). The GFZ analysis results (refractivity and dry temperature profiles) agree very well with UCAR. Differences above $30 \mathrm{~km}$ in refractivity and dry temperature can be explained by the application of different algorithms for the optimization of the bending angle by UCAR and GFZ (see, e.g., Ao et al. 2003). Below the tropopause the presence of water vapor leads to a cold bias of the dry temperature profiles compared to ECMWF wet temperatures [see, e.g., Kursinski et al. (1997) for the definition of dry temperature]. This difference can be regarded as a measure for the water vapor itself and is large for the tropical profile shown in Fig. 7. We note that this cold bias in the dry temperature compared to analysis temperature (wet) is different from the phenomenon of the negative refractivity bias, observed in RO data (e.g., Beyerle et al. 2006). Deviations in the lower troposphere are probably related to differences of the application of the FSI technique by both centers and will be investigated in more detail in future studies utilizing more extended data sets.

\subsection{Near-Real-Time Data Provision for Numerical Weather Forecast}

The year 2006 marks a milestone for the use of GPS as a platform for atmospheric remote sensing, eleven years after the US Air Force announced on 17 July 1995 the full operational capability of the GPS. Both ground and also spacebased (RO) data have started to be used continuously to improve regional and global weather forecasts. Pioneering work with respect to the RO data use for global numerical weather prediction was performed at the Met Office, ECMWF and NCEP using operationally available CHAMP data (e.g., Healy et al. 2005; Healy and Thepaut 2006; Cucurull et al. 2007). The large volume of data, available from FORMOSAT-3/COSMIC since 2006, is a further major impetus for these activities. These data currently form the major share of the operationally available GPS RO data. Continuous assimilation of GPS RO started on 26 September 2006 with CHAMP and GRACE-A at the Met Office (FORMOSAT-3/COSMIC since 15 May 2007), with FORMOSAT-3/COSMIC, CHAMP and GRACE-A on 12 December 2006 at ECMWF and on 22 March 2007 at JMA (Japan Meteorological Agency) with CHAMP. NOAA/NCEP (National Oceanic and Atmospheric Administration/National Center for Environmental Prediction) at US activated the operational assimilation of GPS RO data on 1 May 2007, Meteo France on 5 September 2007. A further boost for these RO related activities to improve global weather forecasts is expected from the GRAS data, recorded aboard the MetOp satellite, however these data are scheduled for availability in 2008.

The current near-real time activities for CHAMP and GRACE-A are funded within an international research project (NRT-RO, Near-Real Time Radio Occultation) by the German Ministry for Education and Research within the GEOTECHNOLOGIEN research programme (www.geotechnologien.de). The primary goals of the project are the 
development of software modules for the precise and rapid derivation of GPS and LEO satellite orbits and globally distributed atmospheric profiles from GPS SST data, the demonstration of a near-real time provision of atmospheric data from CHAMP and GRACE-A with corresponding assimilation in global weather models from ECMWF, the Met Office and the German Weather Service. Additional centers, as, e.g., JMA, Meteo France, NOAA/NCEP, and Environmental Center (Canada) also make use of the project data. A major goal of NRT-RO is to reach an average delay between measurement and provision of the corresponding atmospheric profile of about 2 hours. The provision of NRT occultation data for weather centers started on 28 November 2005. In this first stage of the project, e.g., an average delay of parallel CHAMP and GRACE-A measurements of less than 4 hours was reached for a period of 41 days in January/February 2006 (see also Fig. 8). This was the first NRT demonstration for a two-satellite GPS RO constellation. The data were used for investigations to characterize the impact of CHAMP and GRACE-A bending angles to global weather forecasts at ECMWF (Healy et al. 2007).

A significant prerequisite for the initial NRT activities at GFZ was and is the provision of NRT orbit data for the GPS and CHAMP/GRACE-A satellites. For this purpose a specific data product was defined already in 2003, the Ultra Rapid Science Orbit (USO). These data are calculated with a fixed 3 hourly period for the GPS and LEO satellites, independent from the occurrence of data download at the polar receiving station at Ny Ålesund (see section 3.1). The accuracy of USO is only slightly worse compared to the RSO data (see section 3.2); the main difference in generating USO and RSO is a different GPS ground station data handling and quality control settings to derive GPS orbit data (for details see, e.g., König et al. 2006). To illustrate this, Fig. 9 shows results of a comparison of CHAMP and GRACE-A USO data with SLR measurements. In 2007 it yields an average RMS of $8.0 \mathrm{~cm}$ for CHAMP and $5.7 \mathrm{~cm}$ for GRACE-A.

Although the provision of atmospheric data from CHAMP based on the 3 hour USO period stimulated the use of GPS RO at several Numerical Weather Prediction (NWP) centers significantly, the resulting time delay for the profiles of around $4 \mathrm{~h}$ (see Fig. 8) is insufficient to satisfy the requirement for a maximum latency of $1-4 \mathrm{~h}$ for global prediction (WMO, World Meteorological Organization, TD No. 913, SAT-21, 28/9/1998). For that reason the development of an improved NRT orbit and occultation processing system was started. The main prerequisite for this development was the adaptation of the periods of the orbit and occultation processing to the times of the LEO data download at the polar receiving station at Ny Ålesund around every $1.5 \mathrm{~h}$.

A crucial task is the development of an appropriate system for the near-real time calculation of GPS and LEO orbits. Details of the system were described by Michalak et al. (2007b). Three appropriate, but alternative processing chains were implemented to find the optimal method. The resulting quality of the data products and corresponding time delays were evaluated in detail. The first, called IGU-based (International GNSS Service Ultra rapid orbits and clocks) chain, produces lower accuracy LEO orbits ( $\sim 25 \mathrm{~cm}$ for position; $0.3 \mathrm{~mm} \mathrm{~s}^{-1}$ for velocity error; 9.7 - $11.5 \mathrm{~cm}$ SLR RMS) but with a low latency of $\sim 13 \mathrm{~min}$ only. The second chain, GPS-based, due to a GFZ based

(a) Electron Density $\mathrm{N}_{\mathrm{e}}$ and Plasma Freqency $\mathrm{f}_{\mathrm{p}}$

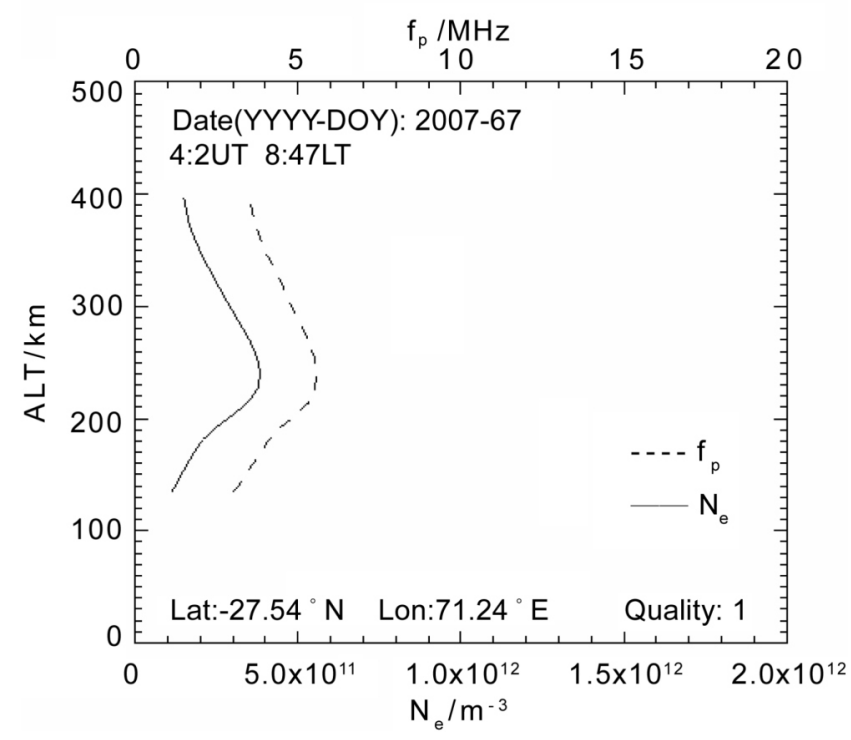

(b) Electron Density $\mathrm{N}_{\mathrm{e}}$ and Plasma Freqency $\mathrm{f}_{\mathrm{p}}$

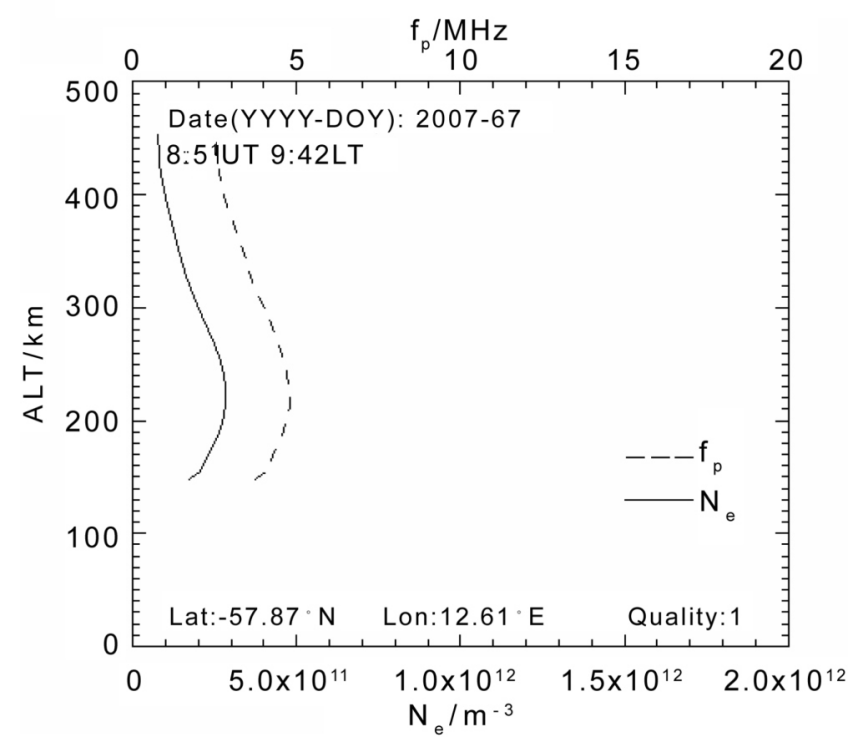

Fig. 6. Two examples of initial vertical ionospheric profiles (electron density and corresponding plasma frequency $f_{P} v$ s. altitude), derived from GRACE-A occultation measurements on 8 March 2007 (for details see text). 
estimation of 5-min GPS orbits and clocks, produces more accurate LEO orbits ( $12-13 \mathrm{~cm}$ for position; $0.14 \mathrm{~mm} \mathrm{~s}^{-1}$ for velocity; $\sim 7$ - 9 cm SLR RMS) with a latency of 33 min. This latency is mainly driven by waiting for complete ground data from IGS data base. The third chain, based on IGU predicted orbits, but estimated dense 30-s clocks, produces the most precise LEO NRT orbits $(10 \mathrm{~cm}$ for position; $0.1 \mathrm{~mm} \mathrm{~s}^{-1}$ for velocity; $4.5-6.4 \mathrm{~cm}$ SLR RMS) with a latency of $\sim 30 \mathrm{~min}$. This chain is potentially the most suitable for high precision NRT applications and will be used as the primary method for the new NRT mode. But also the two alternative approaches would assure a generation of occultation products with a maximum delay well below three hours and could be used in case of failure of the primary chain.

On 17 April 2007 (activation of the new NRT mode) data from the new processing system for CHAMP were monitored by the Met Office (GRAS-SAF). All of the 157

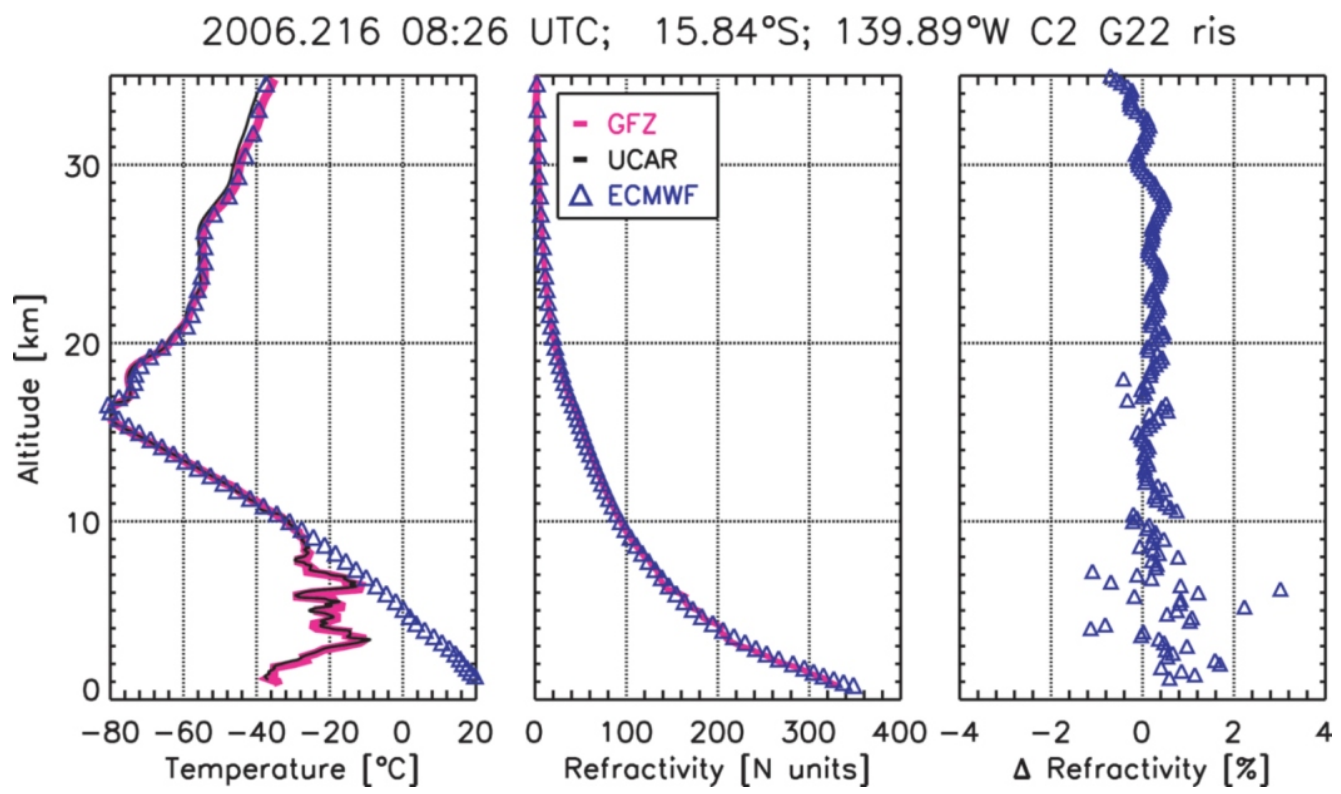

Fig. 7. First rising atmospheric profile, derived from FORMOSAT-3/COSMIC GPS radio occultation data (red) using the GFZ inversion software applied to excess phase and navigation bit information provided by UCAR (for details see text). The profile (left: dry temperature; middle: refractivity $\mathrm{N}$ ) is compared with UCAR (black) and ECMWF "wet" temperature and refractivity (blue triangles). The fractional refractivity difference $\left(\mathrm{N}_{\mathrm{UCAR}}-\mathrm{N}_{\mathrm{GFZ}}\right) / \mathrm{N}_{\mathrm{UCAR}}$ (in \%) is shown right. For details see text.
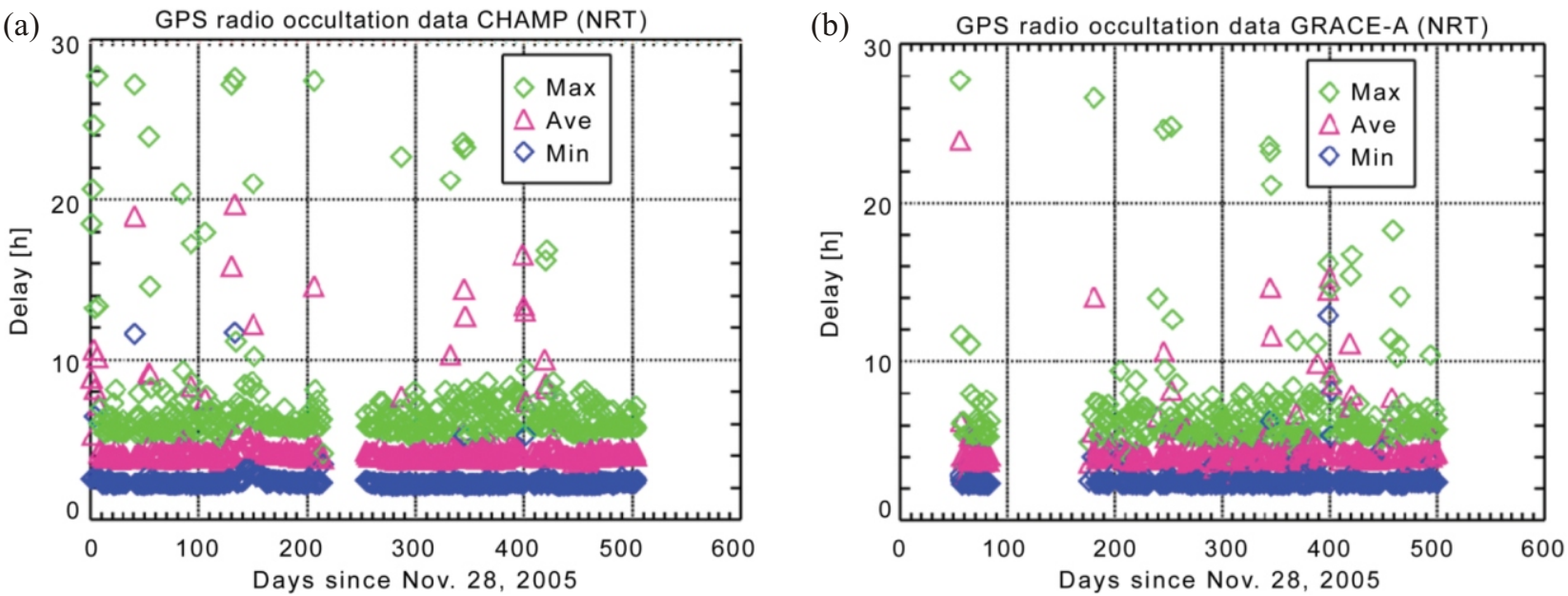

Fig. 8. Mean daily time delay (red triangles) between the measurement and availability of corresponding analysis results at GFZ since 28 November 2005 until March 2007 for (a) CHAMP and (b) GRACE-A. Blue and green diamonds indicate the minimum and maximum time delay for individual profiles each day. 
(a)

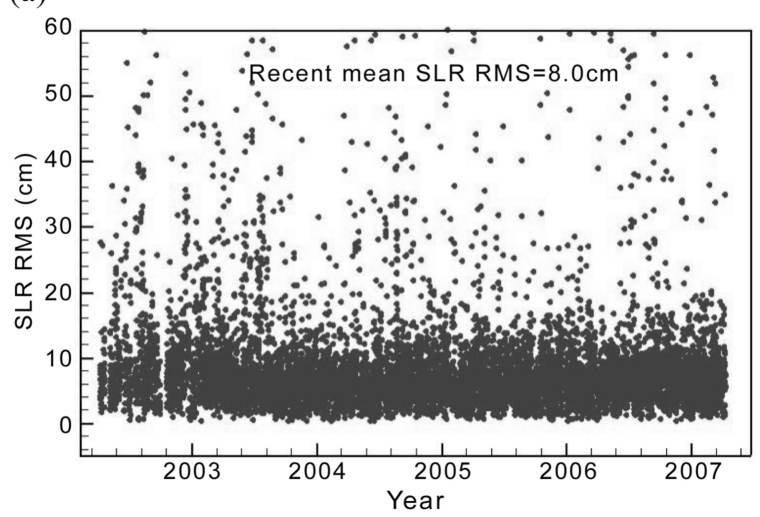

(b)

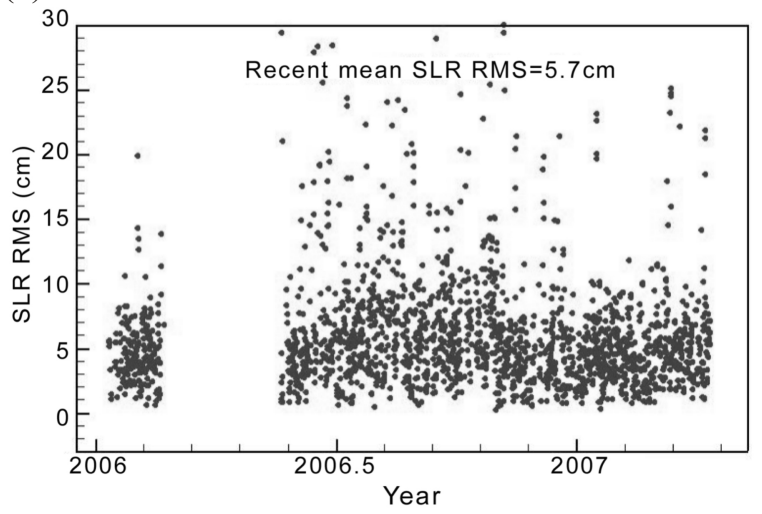

Fig. 9. Comparison of Ultra Rapid Science Orbits (USO) with SLR measurements. (a) CHAMP (9 April 2002 - 12 April 2007). (b) GRACE-A (11 January 2006 - 12 April 2007). For 2007 the mean RMS for CHAMP is $8.0 \mathrm{~cm}$ and for GRACE-A is $5.7 \mathrm{~cm}$.

profiles reached the weather center within $2 \mathrm{~h} 54 \mathrm{~min}$, amounting to an average delay of $1 \mathrm{~h} 44 \mathrm{~min}$ (Fig. 10). The corresponding quality monitoring plot is shown in Fig. 11. The comparison shows in general only small $(<1 \%)$ deviations between measurements and analysis and the results are nearly identical with those from the "older" NRT mode but with larger latency of about a $4 \mathrm{~h}$ mean delay (see Fig. 5). It is beyond the scope of this paper to discuss the differences in more detail, which can be caused by uncertainties of the measurements but also of the meteorological analysis. Current activities focus to the stabilization of the new processing mode for operational data provision and also inclusion of the GRACE-A into the new NRT mode.

\section{APPLICATIONS FOR GPS RO DATA}

The availability of the measurements from FORMOSAT-3/COSMIC significantly increases the data base for various applications of GPS RO data in atmospheric research (Fig. 12). We investigated the period from 1 October to 31 December 2006 in more detail. The overall amount of GPS RO data (calibrated atmospheric excess phases) comprises 183976 globally distributed measurements $(\sim 2000$ daily). FORMOSAT-3/COSMIC data form the major share (152790 measurements, 83.0\%), followed by CHAMP (17991 measurements, 9.8\%) and GRACE-A (13195 measurements, 7.2\%). Even though the FORMOSAT-3/COSMIC data clearly dominate the occultation data base, the share of CHAMP and GRACE-A is significant (17\%). Regions with maximum number of occultations per pixel are the latitude bands around $\sim 25^{\circ}$ and $\sim 50^{\circ}$ North and South. The equator region exhibits the lowest number of occultations per pixel.

Another, more specific, view to the data availability in the lower troposphere is offered by Fig. 13. It shows the percentage of profiles reaching altitudes of about 1 and $0.5 \mathrm{~km}$, respectively for a 3 month period starting from 1 August 2006. The red areas indicate regions with nearly perfect penetration down to 0.5 or $1 \mathrm{~km}$ above mean sea level (MSL), respectively. For the dark blue or black regions there are less or no data available. This reflects the global topography, e.g., mountain regions as the Andes, Himalayas, Rocky Mountains or Greenland and Antarctica. For large areas the majority of the FORMOSAT-3/COSMIC profiles reach deep to the troposphere, in the winter hemisphere (here: South) above oceans even down to $0.5 \mathrm{~km}$. These characteristics of the FORMOSAT-3/COSMIC data allows significantly improved investigations concerning the Planetary Boundary Layer (PBL, Sokolovskiy et al. 2006b) compared to the CHAMP mission (e.g., von Engeln et al. 2006). Knowing the properties of the PBL, and in particular its depth (height of its top), is important for understanding transport processes in the troposphere, weather prediction and climate monitoring (e.g., Garratt 1994).

In the following we present selected examples for applications and compare results from CHAMP with those from CHAMP+FORMOSAT-3/COSMIC+GRACE-A.

\subsection{Global Tropopause Parameters from Radio Occultation Data}

The tropopause (TP) region is one of the key regions of the atmosphere. It separates the troposphere and stratosphere that have fundamentally different characteristics with respect to chemical composition and static stability. Therefore the determination of TP parameters, such as altitude or temperature, on a global scale is an important goal for many branches in atmospheric research.

With regard to the current climate change discussion, TP parameters have received more attention in recent years since they are used to describe climate variability and change. The global mean TP altitude shows an increase in 


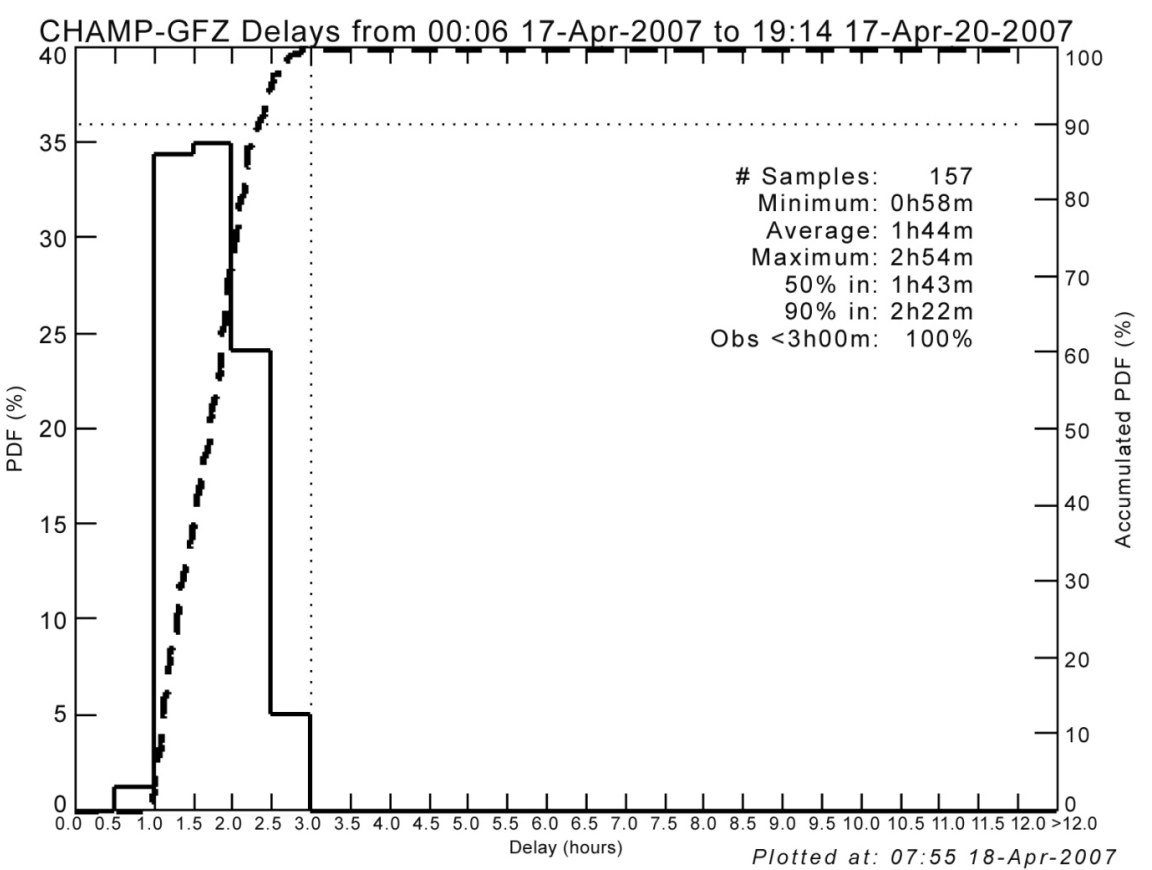

Fig. 10. Monitoring plot (GRAS-SAF, Met Office) for a time delay of CHAMP near-real time data products from 17 April 2007 . A mean delay between measurement and monitoring at the Met Office of $1 \mathrm{~h} 44$ min was observed, all 157 profiles arrived within $2 \mathrm{~h} 54$ min after measurement (http://monitoring.grassaf.org).

GFZ processed CHAMP data, global

Refractivity bias and standard deviation plots

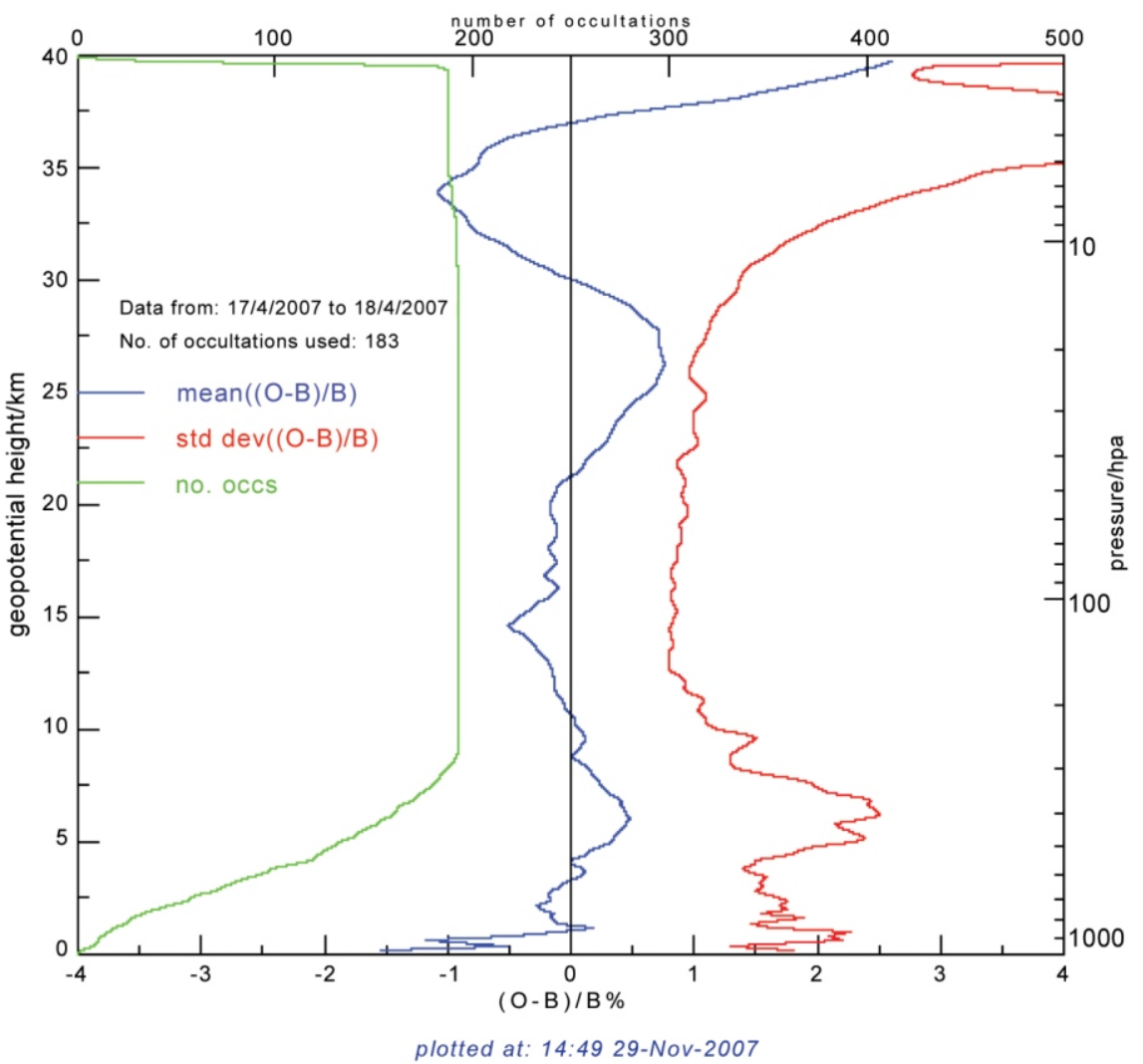

Fig. 11. Monitoring plot (GRAS-SAF, Met Office) for the deviation of CHAMP near-real time refractivity profiles from the Met Office global model (blue: bias; red: RMS) for 17 April 2007. The right plot shows the number of provided data per altitude. 

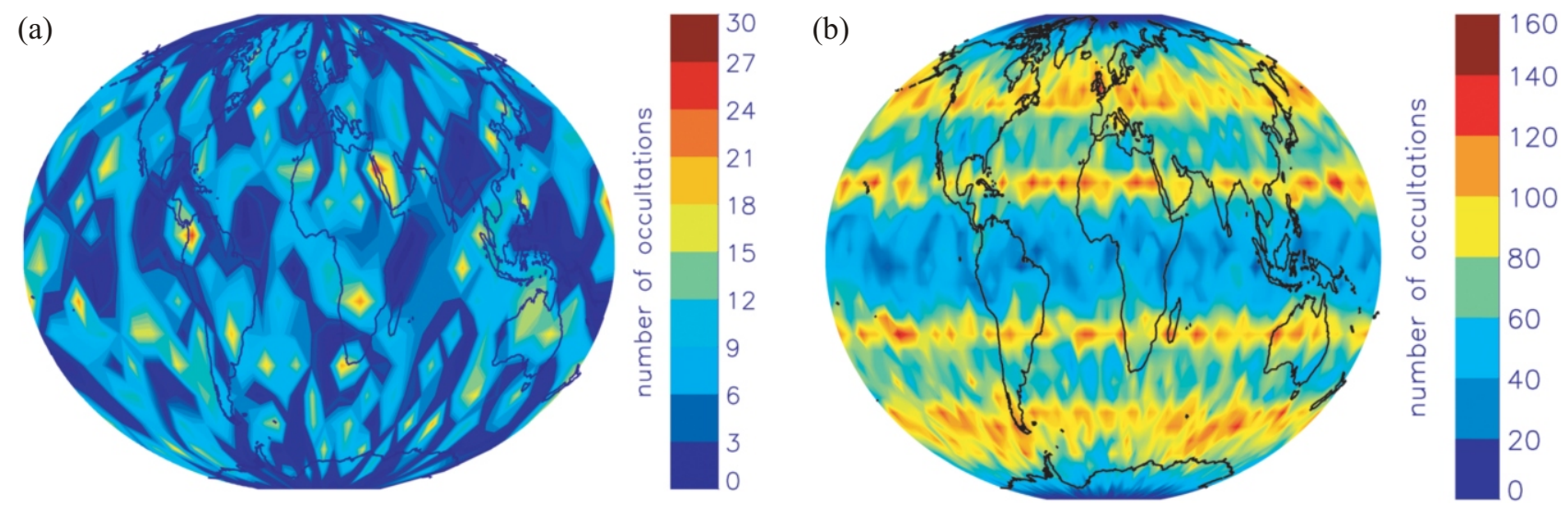

Fig. 12. Availability of GPS RO data (measurements per pixel) for global investigations between 1 October and 31 December 2006 . (a) for CHAMP (latitude/longitude resolution $10 \times 10^{\circ}$ ); (b) for CHAMP+GRACE-A+FORMOSAT-3/COSMIC $\left(5 \times 5^{\circ}\right)$. Please note the different scale .

(a)

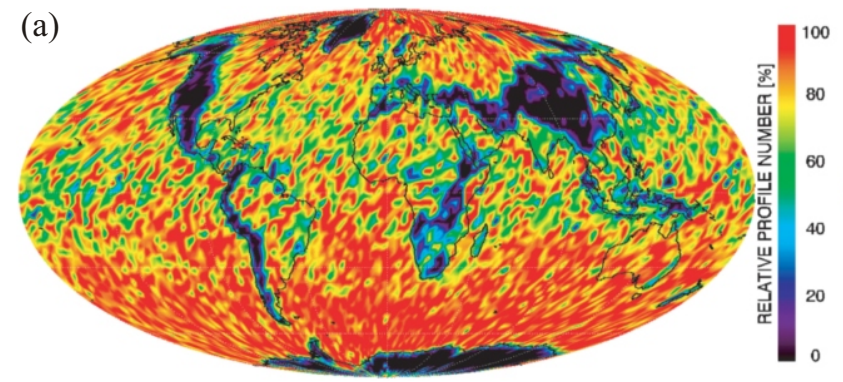

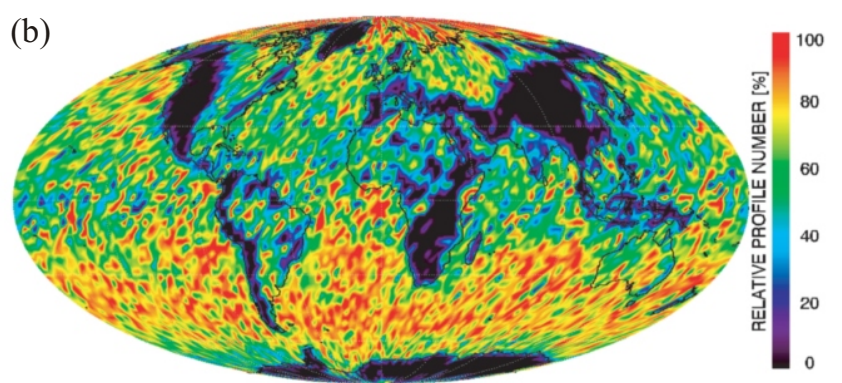

Fig. 13. Global availability $\left(5 \times 5^{\circ}\right)$ of GPS RO data from FORMOSAT-3/COSMIC (OpenLoop Tracking, UCAR profiles) for the (a) 900 hPa ( $\sim 1 \mathrm{~km}$ altitude) and (b) $950 \mathrm{hPa}(\sim 0.5 \mathrm{~km}$ altitude) pressure level between 1 August and 31 October 2006 . The given number corresponds to the fraction of profiles reaching the respective altitude.

reanalyses and radiosonde observations over the last decades and seems to be a more sensitive indicator for climate change as the Earth's surface temperature (Sausen and Santer 2003). Another application area of TP studies deals with the role of the TP region in the stratosphere-troposphere exchange. In this context multiple tropopauses or TP break regions are important because in these regions most of the exchange processes take place (e.g., Pan et al. 2004).

One important data source for the determination of TP parameters are radiosondes. Despite good vertical resolution of the radiosonde data, global coverage is impossible. In contrast, the RO technique offers both global coverage but good vertical resolution as well and is therefore notably applicable for detailed atmospheric monitoring and climate studies (Leroy et al. 2006). Since the availability of GPS RO data starting with the GPS/MET experiment (1995 - 1997) several studies concerning the upper troposphere and lower stratosphere (UTLS) region were performed using the consecutive RO missions (CHAMP, SAC-C, GRACE and FORMOSAT-3/COSMIC).

First results for the tropical TP region using the GPS/ MET data were published by Nishida et al. (2000) and
Randel et al. (2003). Applications of CHAMP RO data to that region were shown by Schmidt et al. (2004) and Borsche et al. (2007), a global analysis of TP parameters from CHAMP and SAC-C was made by Schmidt et al. (2005b). The first climatology and observational characteristics of multiple tropopauses was accomplished by Schmidt et al. (2006) and Randel et al. (2007). The recently launched RO satellite missions, especially FORMOSAT-3/COSMIC, provide a data base for TP studies with significantly higher temporal and spatial resolution and generally open new perspectives for monitoring the UTLS region.

As an example Fig. 14 shows the global CHAMP thermal lapse rate tropopause (LRT) altitude (Fig. 14a) for October 2006 for a latitude/longitude resolution of 10 degrees. The definition of the World Meteorological Organization (WMO) was used for the determination of the LRT (WMO 1957). According to this report the (first) thermal tropopause is defined "as the lowest level at which the lapse rate decreases to $2^{\circ} \mathrm{C} \mathrm{km}^{-1}$ or less, provided also the averaged lapse rate between this level and all higher levels within $2 \mathrm{~km}$ does not exceed $2^{\circ} \mathrm{C} \mathrm{km}^{-1}$ ". The LRT algorithm applied for the GPS RO data is described in detail by Schmidt et al. (2005b). 
For October 2006 a total number of 4722 CHAMP temperature profiles is available where a TP could be successfully determined. White areas represent latitude/longitude bins with no data. The typical TP altitude structure with the maximum in the tropics, the transition zone in the subtropics (20 $-40^{\circ}$ on both hemispheres) and the lowest TP altitude in the polar regions is clearly visible. With the additional 3882 GRACE profiles for October 2006 the horizontal resolution is not improved significantly (not shown here). Figure 14b presents the LRT altitude from CHAMP, GRACE, and FORMOSAT-3/COSMIC with a total number of 46735 successfully determined TPs. Due to the FORMOSAT-3/COSMIC data the horizontal resolution could be improved to $2.5 \times 2.5$ degree in latitude and longitude. This allows a much better discussion of the TP structure, especially in the sub-tropics.

\subsection{Global Water Vapor Distribution}

Water vapor plays a crucial role in weather, climate, and hydrology. It is a key element of the atmospheric greenhouse effect and the working of the hydrological cycle; both support the sustainability of life on Earth. The hydrological cycle describes the movement of water, in all three phases, within and between the Earth's atmosphere, oceans, and continents. In the vapor phase, water can move quickly through the atmosphere and redistributes energy associated with its evaporation and recondensation. The movement of water vapor through the hydrological cycle is strongly coupled to precipitation and soil moisture, which have important practical implications. The basic operation of the hydrologic cycle is well known, but some details are poorly understood, mainly because we do not have sufficiently good observations of water vapor. In addition, monitoring of long-term changes in water vapor, which are closely linked to other climate variations and trends, is needed to both predict and detect changes.

These are more general reasons to investigate, if global water vapor distributions, derived from GPS occultation measurements, may help to extend our knowledge on the hydrological cycle and its variations.

Refractivity data from CHAMP (processed by GFZ), GRACE-A (processed by GFZ) and FORMOSAT-3/COSMIC (processed by UCAR) data were used to derive vertical water vapor profiles (specific humidity) using the DWVP (Direct Water Vapor Pressure) method, introduced by Heise et al. (2006). Figure 15 shows monthly mean global water vapor distributions based on CHAMP and CHAMP+
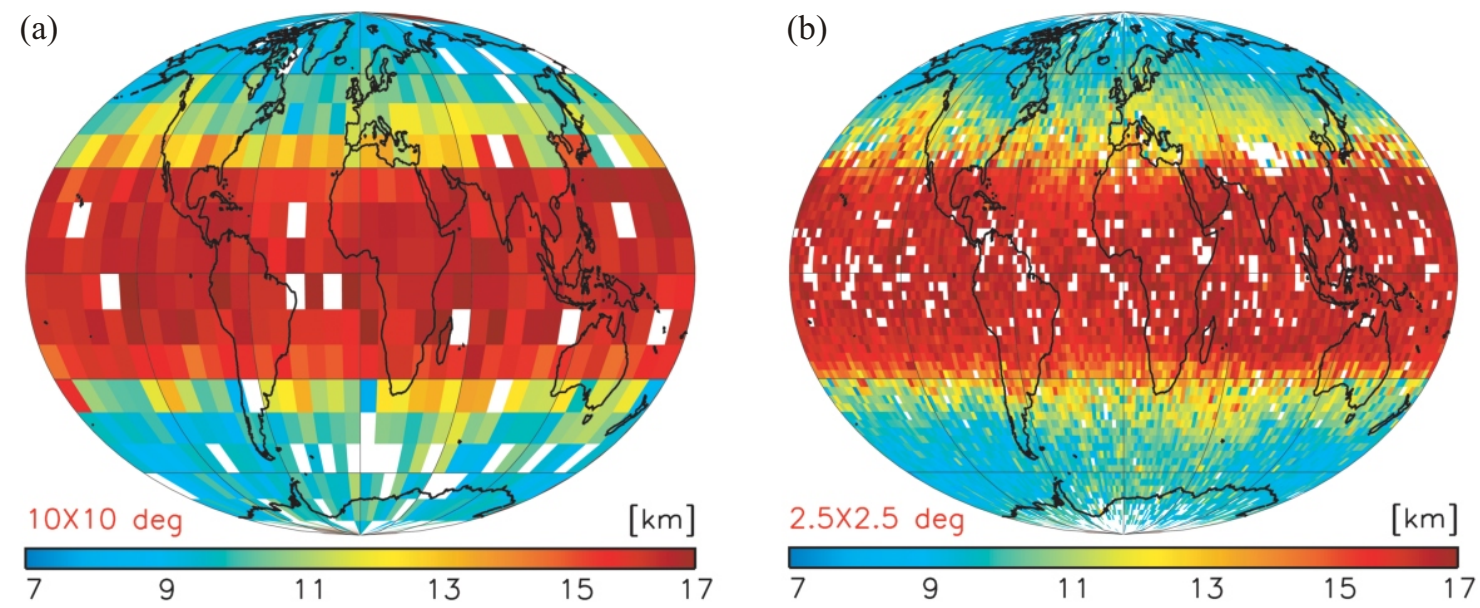

Fig. 14. Mean global tropopause altitude (LRT) for October 2006 derived from (a) CHAMP with a horizontal resolution of $10 \times 10$ degree and from (b) CHAMP, GRACE-A, and FORMOSAT-3/COSMIC (2.5 × 2.5 degree resolution).
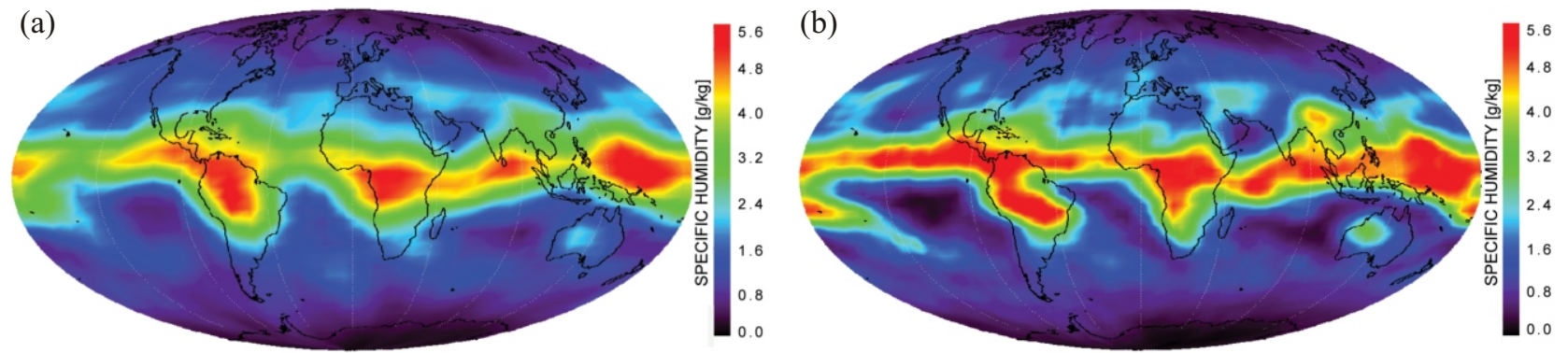

Fig. 15. Global distribution of the mean specific humidity at $600 \mathrm{hPa}$, derived from (a) CHAMP data $\left(5 \times 10^{\circ}\right.$ latitude/longitude) and (b) CHAMP+GRACE-A+FORMOSAT-3/COSMIC $\left(2.5 \times 5.0^{\circ}\right)$ for October 2006. 
GRACE-A+FORMOSAT-3/COSMIC data. This illustrates the capabilities of the growing RO multi-satellite constellation for global water vapor monitoring especially in the mid troposphere region. While CHAMP alone is only capable of giving rough structures of the monthly mean distribution (Fig. 15a), the multi-satellite constellation (Fig. 15b) allows for much more detailed information. This is visible especially in the tropical region where the CHAMP data are obviously too sparse to reproduce the strong water vapor gradients connected e.g., with the position of the inner tropical convergence zone or cold sea currents (e.g., the Humboldt Current).

\subsection{Global Investigations of Ionospheric Irregularities}

The average upper altitude of the high rate $(50 \mathrm{~Hz})$ GPS occultation measurements is set to a value between 120 and 140 km (e.g., CHAMP: 135 km; GRACE-A: 140 km; FORMOSAT-3/COSMIC: $120 \mathrm{~km}$, see Fig. 16). This allows the investigation of another interesting atmospheric phenomenon: plasma irregularities of the lower ionosphere, in more detail the formation of thin ionization layers (sporadic E-layer, Es). The observation of the global distribution, seasonal and diurnal behavior of these irregularities gives information on atmospheric dynamics, electrodynamics and coupling processes with the neutral atmosphere. It is expected that the characteristics of the sporadic E occurrence will provide information on the impact of solar variability, the coupling to the geomagnetic field and on anthropogenic effects on the upper atmosphere. A global monitoring of sporadic $\mathrm{E}$ would also allow for an improved selection of perturbation-free radio links for communication and navigation (Hocke and Tsuda 2001; Hocke et al. 2001 and references therein; $\mathrm{Wu}$ et al. 2005). Generally the mechanism for the

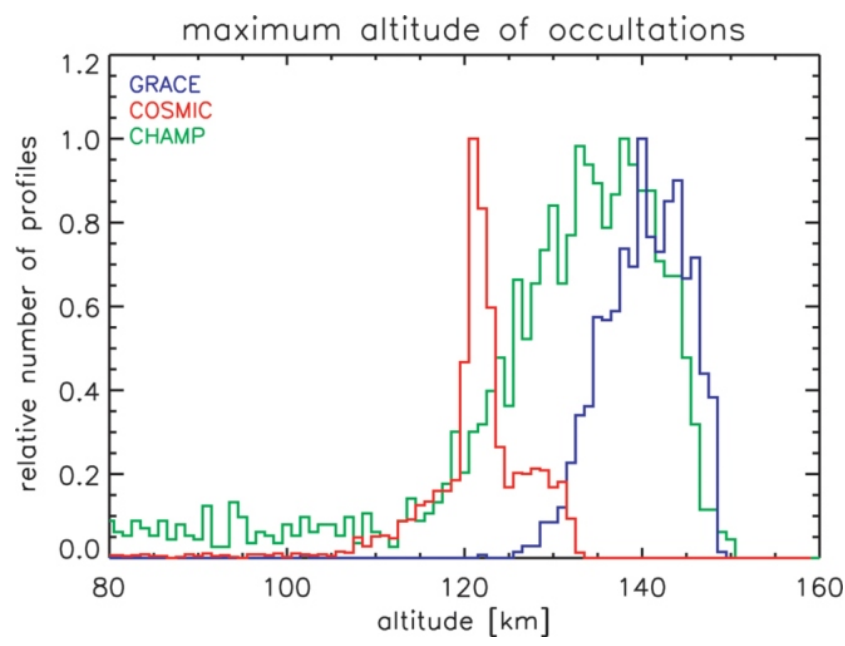

Fig. 16. Distribution of maximum altitude of the GPS radio occultation data (high rate, $50 \mathrm{~Hz}$ ) from CHAMP, GRACE-A and FORMOSAT-3/COSMIC. formation of sporadic E-layers is well understood from ground-based measurements. Also early detailed global maps of sporadic E occurrence were generated based on measurements of a large ionosonde network during the International Geophysical Year in 1958 (Hocke et al. 2001). These maps are mainly based on ground measurements and suffer from the fact that only a small amount of data is available over ocean and polar regions which cover more than three quarters of the Earth's surface. Satellite data would allow for an improved global characterization of sporadic E. GPS radio occultation offers a unique tool for such investigations. For the first time the long-term data set of CHAMP (2002 - 2007) allows detailed seasonal, diurnal and also the start of climatological studies.

We derived the location of the sporadic E-layers using amplitude variations of the $\mathrm{RO}$ signal as an indicator (Wickert et al. 2004b, Arras et al. 2008). Figure 17 shows initial results of these investigations and demonstrates that the availability of the FORMOSAT-3/COSMIC data allows the characterization of the global distribution with unprecedented resolution in time and space (Arras et al. 2008). With
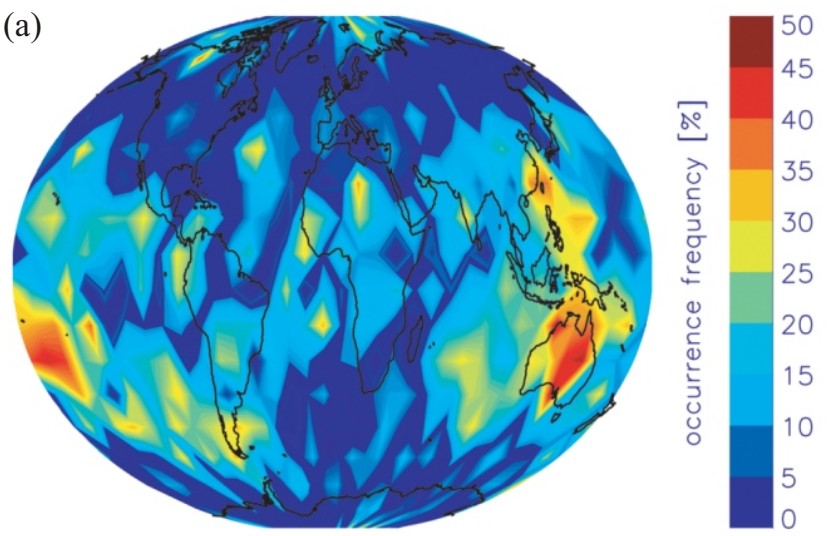

(b)
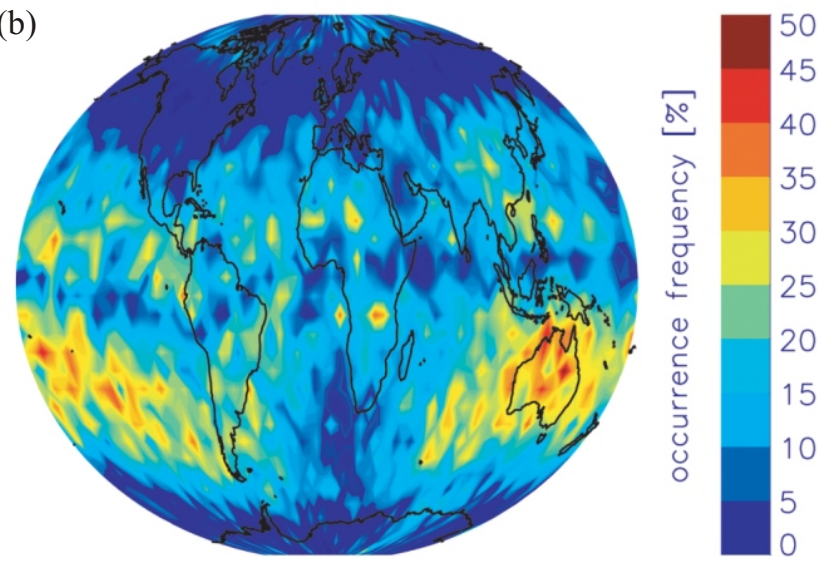

Fig. 17. Occurrence frequency (in \%) of sporadic E-layers, derived from GPS radio occultation data for autumn 2006 (September, October, and November). (a) CHAMP (horizontal resolution $10 \times 10^{\circ}$ latitude/longitude); (b) CHAMP+GRACE-A+FORMOSAT-3/COSMIC $\left(5 \times 5^{\circ}\right)$. 
an occurrence frequency of up to around $50 \%$ of all occultations in particular regions, sporadic $\mathrm{E}$ is a significant phenomenon in the lower ionosphere. It appears preferentially on the summer hemisphere and is not uniformly distributed in longitude. With the much higher number of FORMOSAT-3/COSMIC data compared to CHAMP and GRACE-A a significantly better spatial resolution is reached. Thus, it is possible to better identify regions where Es preferably appears (e.g. the southern hemispheric Pacific region including Australia in the southern hemispheric summer). This observation indicates a correlation with the amount of incident solar radiation, although the gap above the South Atlantic region cannot be explained based on this fact. The occurrence of Es also strongly exhibits daily and annual variations, which will be investigated in more detail in the future with the GPS RO data base. One of the already observed features is the preferential occurrence of midlatitudes Es during the daytime on the respective summer hemisphere.

\section{SUMMARY AND OUTLOOK}

The status of the operational data analysis of CHAMP and GRACE-A radio occultation measurements at GFZ were reviewed and complemented by an overview of the initial results of the FORMOSAT-3/COSMIC data analysis and applications at GFZ. GPS radio occultation data from the current missions are operationally assimilated to improve global weather forecasts at different centers, a milestone for the reputation of the GPS RO technique as an established remote sensing technique. In particular, the significantly increased number of globally distributed profiles from FORMOSAT-3/COSMIC (compared to the current available data) significantly advances the application of GPS RO in atmospheric research with relevance to weather forecasting and climate change related studies. This was demonstrated by the derivation of global tropopause characteristics, water vapor distributions and characterization of plasma irregularities in the lower ionosphere based on CHAMP, GRACE-A and FORMOSAT-3/COSMIC data. The much higher GPS RO data availability since 2006 is complementary to the unique long-term data set from CHAMP, which allows initial climatological investigations.

GNSS (Global Navigation Satellite Systems; in a more general sense than GPS) radio occultation is on its way to become an established atmospheric remote sensing technique. This role will be strengthened by additional and new receivers in space, by the future availability of signals from the GALILEO and the currently recovered GLONASS navigation satellite systems and also by the availability of new GNSS signals (e.g. L2C), which will extend the potential of the GNSS radio occultation technique.

The year 2006 marks an important milestone on this successful way with the launch of FORMOSAT-3/COSMIC and the begin of the operational GPS RO data assimilation to improve global weather forecasts.

Acknowledgements We thank all engineers and scientists of the CHAMP and GRACE team for their work, which is the base for our investigations. This includes, in addition to colleagues at GFZ, the work of colleagues at JPL (BlackJack GPS receiver) and at the University of Texas. We also acknowledge UCAR (Boulder, USA) and NSPO (Taiwan) for the free and rapid provision of FORMOSAT-3/COSMIC data and related support. Part of the work for the presented paper was performed by the corresponding author during a research stay at the National Cheng Kung University Tainan at Taiwan where he found a very productive working atmosphere. ECMWF data were provided through the German Weather Service (DWD). The near-real time activities with CHAMP and GRACE-A are supported by the GEOTECHNOLOGIEN research program, funded by the German Ministry for Research and Education (Project NRTRO, Near-Real Time Radio Occultation). The graphics provided by the Met Office were generated under the GRASSAF, which is a partnership between DMI, ECMWF, IEEC, and the Met Office and is partly funded by EUMETSAT.

\section{REFERENCES}

Anthes, R. A., P. A. Bernhardt, Y. Chen, L. Cucurull, K. F. Dymond, D. Ector, S. B. Healy, S. P. Ho, D. C. Hunt, Y. H. Kuo, H. Liu, K. Manning, C. McCormick, T. K. Meehan, W. J. Randel, C. Rocken, W. S. Schreiner, S. V. Sokolovskiy, S. Syndergaard, D. C. Thompson, K. E. Trenberth, T. K. Wee, N. L. Yen, and Z. Zhang, 2008: The COSMIC/ FORMOSAT-3 mission: Early results. Bull. Amer. Meteor. Soc., March, 313-333, doi: 10.1175/BAMS-89-3-313. [Link]

Ao, C., W. Schreiner, and J. Wickert, 2003: First Report on the CHAMP Radio Occultation Intercomparison Study, JPL Publication. 03-016, 10 pp.

Arras, C., J. Wickert, G. Beyerle, S. Heise, T. Schmidt, and C. Jacobi, 2008: A global climatology of ionospheric irregularities derived from GPS radio occultation. Geophys. Res. Lett., 35, L14809, doi: 10.1029/2008GL034158. [Link]

Beyerle, G., T. Schmidt, J. Wickert, S. Heise, M. Rothacher, G. König-Langlo, and K. B. Lauritsen, 2006: Observations and simulations of receiver-induced refractivity biases in GPS radio occultation. J. Geophys. Res., 111, D12101, doi: 10.1029/2005JD006673. [Link]

Borsche, M., G. Kirchengast, and U. Foelsche, 2007: Tropical tropopause climatology as observed with radio occultation measurements from CHAMP compared to ECMWF and NCEP analyses. Geophys. Res. Lett., 34, L03702, doi: 10.1029/2006GL027918. [Link]

Cheng, C. Z., Y. H. Kuo, R. A. Anthes, and L. Wu, 2006: Satellite constellation monitors global and space weather. EOS Trans. $A G U, 87,166$ pp, doi: 10.1029/2006EO170003. [Link] 
Cucurull, L., J. C. Derber, R. Treadon, and R. J. Purser, 2007: Assimilation of global positioning system radio occultation observations into NCEP's global data assimilation system. Mon. Wea. Rev., 135, 3174-3193, doi: 10.1175/ MWR3461.1. [Link]

Dunn, C., W. Bertiger, Y. Bar-Sever, S. Desai, B. Haines, D. Kuang, G. Franklin, I. Harris, G. Kruizinga, T. Meehan, S. Nandi, D. Nguyen, T. Rogstad, J. B. Thomas, J. T., L. Romans, M. Watkins, S.-C. Wu, S. Bettadpur, and J. Kim, 2003: Instrument of grace GPS augments gravity measurements. GPS World, February 1.

Garratt, J. R., 1994: The Atmospheric Boundary Layer, Cambridge Univ. Press, New York, 315 pp.

Healy, S. B., and J. N. Thepaut, 2006: Assimilation experiments with CHAMP GPS radio occultation measurements. Quart. J. Roy. Meteor. Soc., 132, 605-623, doi: 10.1256/ qj.04.182. [Link]

Healy, S. B., A. Jupp, and C. Marquardt, 2005: Forecast impact experiment with GPS radio occultation measurements. Geophys. Res. Lett., 32, L03804, doi: 10.1029/2004GL 020806. [Link]

Healy, S. B., J. Wickert, G. Michalak, T. Schmidt, and G. Beyerle, 2007: Combined forecast impact of GRACE-A and CHAMP GPS radio occultation bending angle profiles. Atmos. Sci. Lett., 8, 43-50, doi: 10.1002/asl.149. [Link]

Heise, S., J. Wickert, G. Beyerle, T. Schmidt, and C. Reigber, 2006: Global monitoring of tropospheric water vapor with GPS radio occultation aboard CHAMP. Adv. Space Res., 37, 2222-2227, doi: 10.1016/j.asr.2005.06.066. [Link]

Hocke, K. and T. Tsuda, 2001: Using GPS to study Plasma Irregularities. GPS World, July.

Hocke, K., K. Igarashi, M. Nakamura, P. Wilkinson, J. Wu, A. Pavelyev, and J. Wickert, 2001: Global sounding of sporadic E layers by the GPS/MET radio occultation experiment. J. Atmos. Sol.-Terr. Phys., 63, 1973-1980, doi: 10.1016/S1364-6826(01)00063-3. [Link]

Jakowski, N., 2005: Ionospheric GPS radio occultation measurements on board CHAMP. GPS Solut., 9, 88-95 doi: 10.1007/s10291-005-0137-7. [Link]

Jakowski, N., A. Wehrenpfennig, S. Heise, Ch. Reigber, H. Lühr, L. Grunwaldt, and T. K. Meehan, 2002: GPS radio occultation measurements of the ionosphere from CHAMP: Early results. Geophys. Res. Lett., 29, 1457, doi: 10.1029/ 2001GL014364. [Link]

Jensen, A. S., M. Lohmann, H. H. Benzon, and A. Nielsen, 2003: Full spectrum inversion of radio occultation signal. Radio Sci., 38, doi: 10.1029/2002RS002763. [Link]

König, R., G. Michalak, K. Neumayer, R. Schmidt, S. Zhu, H. Meixner, and C. Reigber, 2005: Recent developments in CHAMP orbit determination at GFZ. In: Reigber, C., H. Lühr, P. Schwintzer, and J. Wickert (Eds.), Earth Observation with CHAMP: Results from Three Years in Orbit, Springer Berlin Heidelberg New York, ISBN: 3-54022804-7, 65-70, doi: 10.1007/3-540-26800-6_10. [Link]

König, R., G. Michalak, K. Neumayer, and S. Zhu, 2006: Re- marks on CHAMP orbit products. In: Flury, J., R. Rummel, C. Reigber, M. Rothacher, G. Boedecker, and U. Schreiber (Eds.), Observation of the Earth System from Space, Springer Berlin Heidelberg New York, ISBN: 3-54029520-8, 17-26, doi: 10.1007/3-540-29522-4_2. [Link]

Kursinski, E. R., G. A. Hajj, K. R. Hardy, J. T. Schofield, and R. Linfield, 1997: Observing the earth's atmosphere with radio occultation measurements using the global positioning system. J. Geophys. Res., 102, 23429-23465, doi: 10.1029/ 97JD01569. [Link]

Leroy, S. S., J. G. Anderson, and J. A. Dykema, 2006: Testing climate models using GPS radio occultation: A sensitivity analysis. J. Geophys. Res., 111, D17105, doi: 10.1029/ 2005JD006145. [Link]

Michalak, G., J. Wickert, R. König, and M. Rothacher, 2007a: Precise orbit determination of COSMIC/FORMOSAT-3 satellites for radio occultations. EGU Vienna 2007, Geophysical Abstract EGU2007-A-08402.

Michalak, G., J. Wickert, R. König, and M. Rothacher, 2007b: Precise satellite orbit determination for GPS radio occultation in near-real time (NRT). EGU Vienna 2007, Geophysical Abstract EGU2007-A-08740.

Montenbruck, O., A. Yago, H. Bock, T. V. Helleputte, J. V. D. Ijssel, M. Loiselet, C. Marquardt, P. Silvestrin, P. Visser, and Y. Yoon, 2008: Tracking and navigation performance of the GRAS instrument on MetOp-A. GPS Solut., 12, 289-299, doi: 10.1007/s10291-008-0091-2. [Link]

Nishida, M., A. Shimizu, T. Tsuda, C. Rocken, and R. H. Ware, 2000: Seasonal and longitudinal variations in the tropical tropopause observed with the GPS occultation technique (GPS/MET). J. Meteorol. Soc. Jpn., 78, 691-700.

Pan, L. L., W. L. Randel, B. L. Gary, M. J. Mahoney, and E. J. Hintsa, 2004: Definitions and sharpness of the extratropical tropopause: A trace gas perspective. J. Geophys. Res., 109, D23103, doi: 10.1029/2004JD004982. [Link]

Randel, W. J., F. Wu, and W. R. Rios, 2003: Thermal variability of the tropical tropopause region derived from GPS/MET observations. J. Geophys. Res., 108, D1, 4024, doi: 10.1029/2002JD002595. [Link]

Randel, W. J., D. J. Seidel, and L. L. Pan, 2007: Observational characteristics of double tropopauses. J. Geophys. Res., 112, D07309, doi: 10.1029/2006JD007904. [Link]

Reigber, C., H. Lühr, P. Schwintzer, and J. Wickert (Eds.), 2005: Earth Observation with CHAMP - Results from Three Years in Orbit, Springer, Berlin, Heidelberg, New York, ISBN 3-540-22804-7, doi: 10.1007/b138105. [Link]

Rocken, C., R. Anthes, M. Exner, D. Hunt, S. Sokolovskiy, R. Ware, M. Gorbunov, W. Schreiner, D. Feng, B. Herman, Y. H. Kuo, and X. Zou, 1997: Analysis and validation of GPS/MET data in the neutral atmosphere. J. Geophys. Res., 102, 29849-29866, doi: 10.1029/97JD02400. [Link]

Sausen, R. and B. D. Santer, 2003: Use of changes in tropopause height to detect human influences on climate. Meteorol. Z., 12, 131-136, doi: 10.1127/0941-2948/2003/ 0012-0131. [Link] 
Schmidt, T., J. Wickert, G. Beyerle, and C. Reigber, 2004: Tropical tropopause parameters derived from GPS radio occultation measurements with CHAMP. J. Geophys. Res., 109, D13105, doi: 10.1029/2004JD004566. [Link]

Schmidt, T., J. Wickert, G. Beyerle, R. König, R. Galas, and Ch. Reigber, 2005a: The CHAMP atmospheric processing system for radio occultation measurements. In: Reigber, C., H. Lühr, P. Schwintzer, and J. Wickert (Eds.), Earth Observation with CHAMP: Results from Three Years in Orbit, Springer Berlin Heidelberg New York, ISBN: 3-54022804-7, 597-602, doi: 10.1007/b138105. [Link]

Schmidt, T., S. Heise, J. Wickert, G. Beyerle, and Ch. Reigber, 2005b: GPS radio occultation with CHAMP and SAC-C: Global monitoring of thermal tropopause parameters. Atmos. Chem. Phys., 5, 1473-1488.

Schmidt, T., G. Beyerle, S, Heise, J. Wickert, and M. Rothacher, 2006: A climatology of multiple tropopauses derived from GPS radio occultations with CHAMP and SAC-C. Geophys. Res. Lett., 33, L04808, doi: 10.1029/2005GL024600. [Link]

Schreiner, W., C. Rocken, S. Sokolovskiy, S. Syndergaard, and D. Hunt, 2007: Estimates of the precision of GPS radio occultations from the COSMIC/FORMOSAT-3 mission. Geophys. Res. Lett., 34, L04808, doi: 10.1029/2006GL 027557. [Link]

Sokolovskiy, S. V., C. Rocken, D. Hunt, W. S. Schreiner, J. Johnson, D. Masters, and S. Esterhuizen, 2006a: GPS profiling of the lower troposphere from space: Inversion and demodulation of the open-loop radio occultation signals. Geophys. Res. Lett., 33, L14816, doi: 10.1029/2006GL 026112. [Link]

Sokolovskiy, S., Y. H. Kuo, C. Rocken, W. S. Schreiner, D. Hunt, and R. A. Anthes, 2006b: Monitoring the atmospheric boundary layer by GPS radio occultation signals recorded in the open-loop mode. Geophys. Res. Lett., 33, L12813, doi: 10.1029/2006GL025955. [Link]

Tapley, B. D. and Ch. Reigber, 2004: GRACE (Gravity Recovery and Climate Experiment). In: McGraw-Hill Yearbook of Science \& Technology, McGraw-Hill, New York., 135-138.

von Engeln, A., J. Teixeira, J. Wickert, and S. A. Buehler, 2006: CHAMP radio occultation detection of the planetary boundary layer top. In: Foelsche, U., G. Kirchengast, and A. Steiner (Eds.), Atmosphere and Climate: Studies by Occultation Methods, Springer Berlin Heidelberg New York, ISBN 3-540-34116-1, 265-272, doi: 10.1007/3540-34121-8. [Link]

von Engeln, A., C. Marquardt, J. P. Luntama, and J. Wilson, 2007: The GRAS instrument on MetOp: Overview. EGU Vienna 2007, Geophysical Abstract EGU2007-A-09276.

Vorob'ev, V. V. and T. G. Krasnil'nikova, 1994: Estimation of the accuracy of the atmospheric refractive index recovery from Doppler shift measurements at frequencies used in the NAVSTAR system. Phys. Atmos. Ocean, 29, 602-609.

Wehrenpfennig, A., N. Jakowski, and J. Wickert, 2001: A dynamically configurable system for operational processing of space weather data. Phys. Chem. Earth, 26, 601-604, doi:10.1016/S1464-1917(01)00054-X. [Link]

Wickert, J., 2002: The CHAMP-Radio occultation experiment: Algorithms, Processing system and first results (germ.), Scientific Technical Report STR 02/07, GFZ Potsdam.

Wickert, J., C. Reigber, G. Beyerle, R. König, C. Marquardt, T. Schmidt, L. Grunwaldt, R. Galas, T. K. Meehan, W. G. Melbourne, and K. Hocke, 2001a: Atmospheric sounding by GPS radio occultation: First results from CHAMP. Geophys. Res. Lett., 28, 3263-3266, doi: 10.1029/2001GL 013117. [Link]

Wickert, J., R. Galas, G. Beyerle, R. König, and Ch. Reigber, 2001b: GPS ground station data for CHAMP radio occultation measurements. Phys. Chem. Earth, 26, 503-511, doi: 10.1016/S1464-1895(01)00092-8. [Link]

Wickert, J., G. Beyerle, G. A. Hajj, V. Schwieger, and Ch. Reigber, 2002: GPS radio occultation with CHAMP: Atmospheric profiling utilizing the space-based single differencing technique. Geophys. Res. Lett., 29, doi: 10.1029/ 2001GL013982. [Link]

Wickert, J., T. Schmidt, G. Beyerle, R. König, C. Reigber, and N. Jakowski, 2004a: The radio occultation experiment aboard CHAMP: Operational data analysis and validation of vertical atmospheric profiles. J. Meteorol. Soc. Jpn., 82, 381-395, doi: 10.2151/jmsj.2004.381. [Link]

Wickert, J., A. G. Pavelyev, Y. A. Liou, T. Schmidt, C. Reigber, K. Igarashi, A. A. Pavelyev, and S. Matyugov, 2004b: Amplitude variations in GPS signals as a possible indicator of ionospheric structures. Geophys. Res. Lett., 31, L24801, doi: 10.1029/2004GL020607. [Link]

Wickert, J., G. Beyerle, R. König, S. Heise, L. Grunwaldt, G. Michalak, Ch. Reigber, and T. Schmidt, 2005: GPS radio occultation with CHAMP and GRACE: A first look at a new and promising satellite configuration for global atmospheric sounding. Ann. Geophys., 23, 653-658.

Wickert, J., T. Schmidt, G. Beyerle, G. Michalak, R. König, S. Heise, and Ch. Reigber, 2006a: GPS radio occultation with CHAMP and GRACE: Recent results. In: Foelsche, U., G. Kirchengast, and A. Steiner (Eds.), Atmosphere and Climate: Studies by Occultation Methods, Springer Berlin Heidelberg New York, ISBN 3-540-34116-1, 3-16, doi: 10.1007/3-540-34121-8_1. [Link]

Wickert, J., T. Schmidt, G. Michalak, G. Beyerle, S. Heise, B. Tapley, F. Flechtner, and M. Rothacher, 2006b: GPS based atmospheric sounding with CHAMP and GRACE: Preliminary results of comparative data analysis. EGU Vienna 2006, Geophysical Abstract EGU06-A-03737.

WMO, 1957: Definition of the tropopause. WMO Bull., 6, Geneva.

Wu, D. L., C. O. Ao, G. A. Hajj, M. de la Torre Juarez, and A. J. Mannucci, 2005: Sporadic E morphology from GPSCHAMP radio occultation. J. Geophys. Res., 110, A01306, doi: 10.1029/2004JA010701. [Link]

Yunck, T. P., C. H. Liu, and R. Ware, 2000: A history of GPS sounding. Terr. Atmos. Ocean. Sci., 11, 1-20. 